\title{
Experimental Estimation of Journal Bearing Stiffness for Damage Detection in Large Hydrogenerators
}

\author{
Geraldo Carvalho Brito Jr., ${ }^{1,2}$ Roberto Dalledone Machado, ${ }^{2}$ and Anselmo Chaves Neto ${ }^{2}$ \\ ${ }^{1}$ Center for Engineering and Exact Sciences, Western Paraná State University (UNIOESTE), Foz do Iguaçu, PR, Brazil \\ ${ }^{2}$ Numerical Methods for Engineering Graduate Program, Federal University of Paraná (UFPR), Curitiba, PR, Brazil \\ Correspondence should be addressed to Geraldo Carvalho Brito Jr.; gcbritojr@gmail.com
}

Received 28 December 2016; Revised 10 May 2017; Accepted 16 May 2017; Published 27 June 2017

Academic Editor: Marco Belloli

Copyright (c) 2017 Geraldo Carvalho Brito Jr. et al. This is an open access article distributed under the Creative Commons Attribution License, which permits unrestricted use, distribution, and reproduction in any medium, provided the original work is properly cited.

\begin{abstract}
Based on experimental pieces of evidence collected in a set of twenty healthy large hydrogenerators, this article shows that the operating conditions of the tilting pad journal bearings of these machines may have unpredictable and significant changes. This behavior prevents the theoretical determination of bearing stiffness and damping coefficients with an adequate accuracy and makes damage detection difficult. Considering that dynamic coefficients have similar sensitivity to damage and considering that it is easier to monitor bearing stiffness than bearing damping, this article discusses a method to estimate experimentally the effective stiffness coefficients of hydrogenerators journal bearings, using only the usually monitored vibrations, with damage detection purposes. Validated using vibration signals synthesized by a simplified mathematical model that simulates the dynamic behavior of large hydrogenerators, the method was applied to a journal bearing of a $700 \mathrm{MW}$ hydrogenerator, using two different excitations, the generator rotor unbalance and the vortices formed in the turbine rotor when this machine operates at partial loads. The experimental bearing stiffnesses obtained using both excitations were similar, but they were also much lower than the theoretical predictions. The article briefly discusses the causes of these discrepancies, the method's uncertainties, and the possible improvements in its application.
\end{abstract}

\section{Introduction}

Even failures of small proportions may lead large hydrogenerators (LHG) to a long period of unavailability, from several days to some months, causing considerable financial losses. Failures in these machines may also assume catastrophic proportions, with losses of human lives, serious environmental damage, and several years of total or partial unavailability [1]. These facts fully justify the application of condition monitoring techniques to LHG. The basics of these techniques are well known: a significant change in the monitored parameter indicates the development of damage, and the adequate analysis of the symptoms allows the damage diagnosis [2-4].

Vibration-based condition monitoring is the most frequent and successful technique applied to rotating machines [5], especially in the standard machines used in the several branches of the industry. However, LHG are tailor-made rotating machines, of oversize dimensions and vertical assembly, designed and manufactured in small number, to fulfil the specific requirements of each power plant. Minor differences in the design or in the assembly procedures may make the typical vibratory behaviors of two apparently identical LHG, operating in similar conditions, be very different from each other [6].

The dynamic coefficients of journal bearings, bearing stiffness and damping, have major influences on the dynamic behavior of a LHG [7]. As illustrated in what follows, this behavior may experience significant and unpredictable changes due to fluctuations in the journal bearing operating conditions. This creates an additional problem for damage detection in the differentiation of the normal changes in LHG dynamics from the changes originated by the developing of damage.

The influence of the uncertainties in journal bearing operating conditions, like pads clearances, lubricant viscosity, and 
shaft eccentricity, may be analyzed using stochastic modeling techniques $[8,9]$. However, for damage detection purposes, the experimental estimation of bearing dynamic coefficients may be used as an effective solution. The main contribution of this article is the discussion of a method to experimentally estimate the journal bearings stiffnesses to assist damage detection in LHG. Requiring only the lateral shaft relative vibrations and bearing absolute vibrations usually monitored, this method was validated by numerical simulations and by experimental analyses.

All the numerical simulations and experimental analyses mentioned in this article are related to the $700 \mathrm{MW}$ hydrogenerators of Itaipu, a $14000 \mathrm{MW}$ power plant located in the Parana River, belonging to both Brazil and Paraguay governmental electrical utilities holding companies. The rotating speeds of these hydrogenerators are $90.9 \mathrm{r} / \mathrm{min}$ for the 10 units that operate at $50 \mathrm{~Hz}$ and $92.3 \mathrm{r} / \mathrm{min}$ for the remaining 10 units, which produce electrical energy at $60 \mathrm{~Hz}$. Figure 1 shows the generator (1) and turbine (2) rotors, as well as the three tilting pad journal bearings (TPJB) of these machines. The upper bearing is composed of the generator upper shaft (3), pads (6), and bearing bracket (9). The lower bearing is a combined thrust and journal bearing, constituted by the generator lower shaft (4), the thrust block and pads (7), and the thrust bearing bracket (10). The turbine bearing is composed of the turbine shaft (5), pads (8), and turbine headcover (11). Table 1 presents the main data of these journal bearings [10]. This table brings two different clearances, the assembled pad clearance at standstill and the assembled pad clearance in operation. The first value is the clearance adjusted during bearing assembling, by means of wedges inserted in the back of the pads, with the hydrogenerator at standstill. The second value is the clearance when the hydrogenerator is in normal operation, after bearing warming, considering the journal radial increase due to the centrifugal forces and the thermal expansion and due to bearing housing deformation by the action of the turbine axial hydraulic pull, in the specific case of combined bearings. These effects may cause significant reductions in the assembled pad clearance at standstill.

Tiwari et al. [11] consider that the theoretical estimation of bearing dynamic coefficients "has always been a source of error in the prediction of rotor-bearing systems," mainly due to the difficulties of determining bearing operating conditions accurately. This problem is worse in vertical rotating machines, like LHG. For instance, the gaps of two proximity transducers installed $90^{\circ}$ apart in the journal bearings, to measure the shaft relative vibrations, are plotted against each other in the diagrams of Figure 2. The marks on the diagrams are related to the average shaft center position in the journal bearing or the shaft eccentricity. Five measurements were taken during a month (April) and the remaining five were taken eight months later, also over a period of a month (January). In all these measurements, the LHG was healthy and operating in a steady-state condition, with the generator power fixed in a certain load in the range of 470 to $700 \mathrm{MW}$, during more than five hours.

Shaft eccentricity is one of the parameters used to characterize the journal bearing operating condition. Once this parameter is defined, the pads clearances are determined, usually considering the fact that bearing housing is ideal, without dimensional changes [12]. Then, the dynamic coefficients of the journal bearing are determined, considering only the oil film hydrodynamic effects (hydrodynamic model) or including the thermal effects of bearing losses (thermohydrodynamic model) and the deformation effects produced by the oil film pressure (thermoelastohydrodynamic or TEHD model) [13]. The thermal deformations of shaft collar, bearing housing, and support of proximity transducers may have significant influence on the estimated shaft relative position shown in Figure 2. Anyway, this figure indicates that shaft eccentricity may have random and significant variations, which will change bearing dynamic coefficients in a similar way. Therefore, the accurate theoretical determination of these coefficients is impractical, even when using refined TEHD models.

With this motivation, Tiwari et al. [11] organized an extensive review about the experimental estimation of bearing dynamic coefficients, examining almost 300 references on this subject, issued during the past 90 years. These authors emphasize the need of experimental work, using full-scale rotor systems, and the need for validation of dynamic coefficients derived from actual machines in the real operating environment. In a more recent review, Dimond et al. [14] compared theoretical and experimental results, obtained in test rigs, under controlled conditions. This reference brings attention to the uncertainty analysis in the estimation of bearing coefficients and highlights the need of using TEHD models to theoretically determine these coefficients and to consider the effects of bearing heat transfer and of mechanical deformations. This reference remarks that, even in that case, the "agreement between theory and experiment for bearing coefficients is seldom better than $10-20$ percent."

In one of the few references directly applied to vertical hydrogenerators, Gustavsson et al. [15] proposed a method to estimate bearing stiffness and damping coefficients, using the orthogonal components $\left(f_{x}\right.$ and $\left.f_{y}\right)$ of the journal bearing radial force, measured with strain gauges installed in the bearing bracket arms. This method uses the following bearing model with two degrees of freedom (DOF):

$$
\left\{\begin{array}{l}
f_{x} \\
f_{y}
\end{array}\right\}=\left[\begin{array}{ll}
k_{x x} & k_{x y} \\
k_{y x} & k_{y y}
\end{array}\right]\left\{\begin{array}{l}
u_{x} \\
u_{y}
\end{array}\right\}+\left[\begin{array}{ll}
c_{x x} & c_{x y} \\
c_{y x} & c_{y y}
\end{array}\right]\left\{\begin{array}{l}
\dot{u}_{x} \\
\dot{u}_{y}
\end{array}\right\},
$$

where $k_{i j}$ and $c_{i j}$ are the components of stiffness and damping matrices and $u_{i}$ and $\dot{u}_{i}$ are the displacement and velocity components in $X$-direction and $Y$-direction. Bearings were considered isotropic $\left(k_{x x}=k_{y y}=k\right.$ and $\left.c_{x x}=c_{y y}=c\right)$, with negligible cross-coupling effects $\left(k_{x y}=k_{y x}=0\right.$ and $c_{x y}=$ $c_{y x}=0$ ). These effective bearing dynamic coefficients were obtained expressing the former equation in polar coordinates, at different time instants, creating a solvable system of equations. For example, the bearing stiffness estimated in a $238 \mathrm{MW}$ hydrogenerator using this method fluctuated in the range of 0.40 to $0.80 \mathrm{GN} / \mathrm{m}$.

The use of strain gauges to measure the journal bearing radial force is not suitable in the bearings with preloads [15] or those supported by more complex structures. Giving sequence to the previous work, Nässelqvist et al. [16] also 


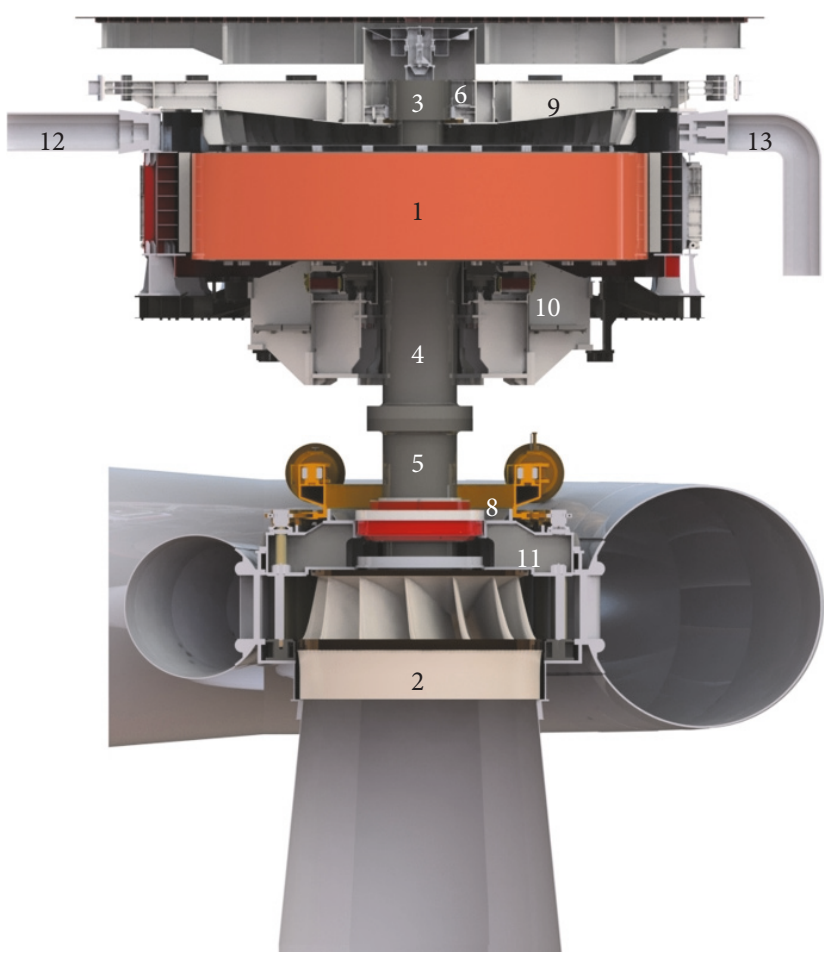

Figure 1: View of Itaipu Power Plant hydrogenerators.

TABLE 1: Main data of the generator upper (UJB), generator lower (LJB), and turbine (TJB) journal bearings.

\begin{tabular}{|c|c|c|c|c|}
\hline Description & Unit & UJB & LJB & TJB \\
\hline Number of pads & - & 16 & 16 & 12 \\
\hline Journal radius & $\mathrm{mm}$ & 1100 & 2600 & 1600 \\
\hline Bearing pad radius & $\mathrm{mm}$ & 1103 & 2604 & 1633 \\
\hline Journal speed & $\mathrm{m} / \mathrm{s}$ & 10.6 & 25.1 & 15.5 \\
\hline Assembled pad clearance at standstill & $\mu \mathrm{m}$ & 500 & 950 & 200 \\
\hline Assembled pad clearance in operation & $\mu \mathrm{m}$ & 200 & 300 & 200 \\
\hline Bearing preload & - & 0.933 & 0.925 & 0.994 \\
\hline Pad pivoting system & - & & Similar to rocker-pivot type & \\
\hline Distance trailing edge-pivot & $\mathrm{mm}$ & 140 & 248 & 250 \\
\hline Pad length & $\mathrm{mm}$ & 350 & 620 & 500 \\
\hline Pad width & $\mathrm{mm}$ & 400 & 310 & 500 \\
\hline Pad mass & $\mathrm{kg}$ & 172 & 290 & 390 \\
\hline Bearing direct stiffness (average) & $\mathrm{GN} / \mathrm{m}$ & 6.70 & 2.85 & 6.70 \\
\hline Bearing global stiffness & $\mathrm{GN} / \mathrm{m}$ & 0.80 & 1.25 & 1.45 \\
\hline Lubricant type & & & Lubrax Turbina Plus 50 & \\
\hline Lubricant viscosity at $40^{\circ} \mathrm{C}$ & Pas & 0.047 & 0.047 & 0.047 \\
\hline Lubricant viscosity at $100^{\circ} \mathrm{C}$ & Pas & 0.0068 & 0.0068 & 0.0068 \\
\hline Lubricant density at $20^{\circ} \mathrm{C}$ & $\mathrm{kg} / \mathrm{m}^{3}$ & 873 & 873 & 873 \\
\hline Lubricant temperature range & ${ }^{\circ} \mathrm{C}$ & $40-55$ & $40-55$ & $40-50$ \\
\hline
\end{tabular}

focused on the bearing radial forces by considering that shaft relative and bearing absolute vibrations are "not sufficient for status determination of a vertical hydropower unit." According to these authors, the use of strain gauges in the pivot pins of the bearing pads gives more resolution to radial force measurement, which, combined with shaft vibrations, allows the calculation of bearing stiffness and damping.

Nässelqvist et al. [17] proposed a methodology for monitoring hydrogenerators, based on their mechanical properties. The journal bearing radial load has an essential function 

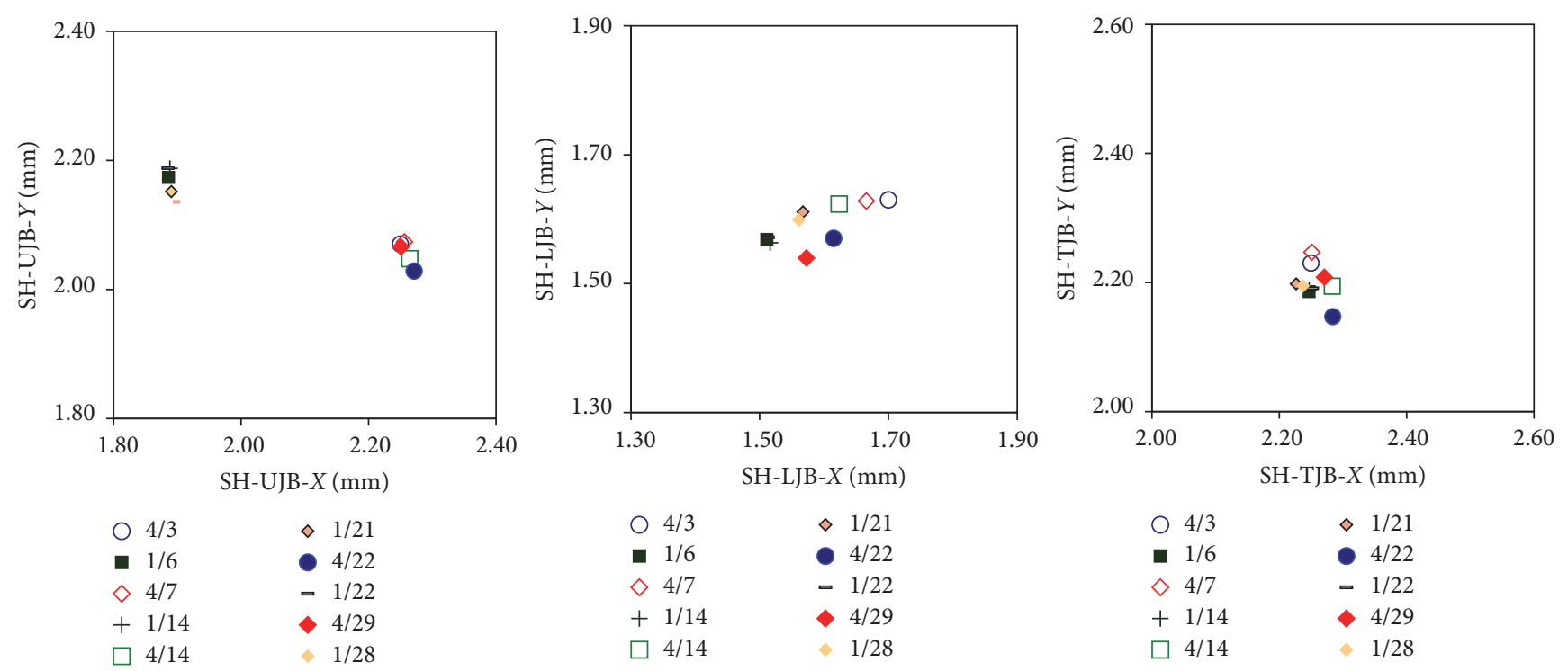

FIGURE 2: Shaft eccentricity in the upper, lower, and turbine journal bearings of a $700 \mathrm{MW}$ hydrogenerator, measured during several months.

in this methodology. Equation (1) is expressed in frequency domain, at a certain frequency $\Omega$, as

$$
\left\{\begin{array}{l}
f_{x} \\
f_{y}
\end{array}\right\}=\left[\begin{array}{ll}
k_{x x}+i \Omega c_{x x} & k_{x y}+i \Omega c_{x y} \\
k_{y x}+i \Omega c_{y x} & k_{y y}+i \Omega c_{y y}
\end{array}\right]\left\{\begin{array}{l}
u_{x} \\
u_{y}
\end{array}\right\},
$$

where $i$ is the imaginary number. Using a commercial rotor dynamic analysis software, these authors calculated the direct and cross-coupled bearing stiffness $\left(k_{x x}, k_{x y}, k_{y x}\right.$, and $\left.k_{y y}\right)$ and bearing damping coefficients $\left(c_{x x}, c_{x y}, c_{y x}\right.$, and $c_{y y}$ ) for a set of several different bearing clearances and shaft relative displacements or shaft eccentricities. By this procedure, a precalculated database was determined, relating journal bearing radial load to the shaft displacements and the bearing clearances. The measurement of shaft relative displacements was improved by using a four-proximitytransducer arrangement, a procedure similar to that applied in generator air gap monitoring, able to compensate shaft and bearing symmetrical thermal expansions. With the measured shaft displacement for a given bearing clearance, the journal bearing radial load may be directly determined using the precalculated database. In an independent research developed simultaneously, Young et al. [18] used a similar procedure in solving a nonlinear hydrogenerator model, reducing the processing time by means of a database containing the journal bearings radial loads calculated previously, for several operating conditions.

Nässelqvist et al. [17] bring a comparison between measured and calculated journal bearing radial loads for a $40 \mathrm{MW}$ vertical hydrogenerator. There is a good agreement for the static load. However, the dynamic load is very apparently overestimated in two times or more the measured dynamic load. Considering that the shaft displacement is measured properly, this effect indicates that the bearing dynamic coefficients determined theoretically, using the commercial software, are overestimated.
A possible explanation for this effect is that the real clearances of the journal bearing are larger than the nominal values. For instance, Figure 3 shows three pad clearances distributions in the upper journal bearing of a LHG. The blue circle shows the bearing nominal clearances and the green closed curve indicates the clearances measured during bearings special commissioning tests [19], when the generator was excited at $0 \mathrm{MW}$. The red outer curve defines the clearances measured at $700 \mathrm{MW}$, also during the mentioned bearing tests. The substantial dimensional changes when the generator is loaded are attributed to the differential heating of bracket arms, originated by the electromagnetic field induced by the generator outputs, components (12) and (13) in Figure 1. This effect is usually disregarded by the most refined bearing models, but it may have significant consequences. It makes bearing anisotropic, with clearances much larger than the nominal values, which decreases the theoretically predicted bearing stiffnesses expressively [12]. The difficulty in the prediction of this and other similar effects justifies the experimental estimation of bearing dynamic coefficients.

\section{Method for the Experimental Estimation of Journal Bearing Stiffness}

2.1. Method Description. Figure 4 shows a simplified model used to derive a method for experimentally estimating the journal bearing stiffnesses, using exclusively the monitored shaft relative and the bearing absolute vibrations. In this figure, $\left(x_{s}, y_{s}\right),\left(x_{b}, y_{b}\right)$, and $\left(x_{f}, y_{f}\right)$ are, respectively, the coordinates of the shaft, the bearing, and the foundation; $f_{x}$ and $f_{y}$ are the components of the rotating force in $X$ direction and $Y$-direction. This model considers that the foundation vibrations at the hydrogenerator rotating speed are negligible. The shaft relative vibrations measured by proximity transducers are given by $u_{x}=\left(x_{s}-x_{b}\right)$ and $u_{y}=$ $\left(y_{s}-y_{b}\right)$, while the bearing absolute vibrations measured by piezoelectric accelerometers are $\ddot{x}_{b}$ and $\ddot{y}_{b}$. 


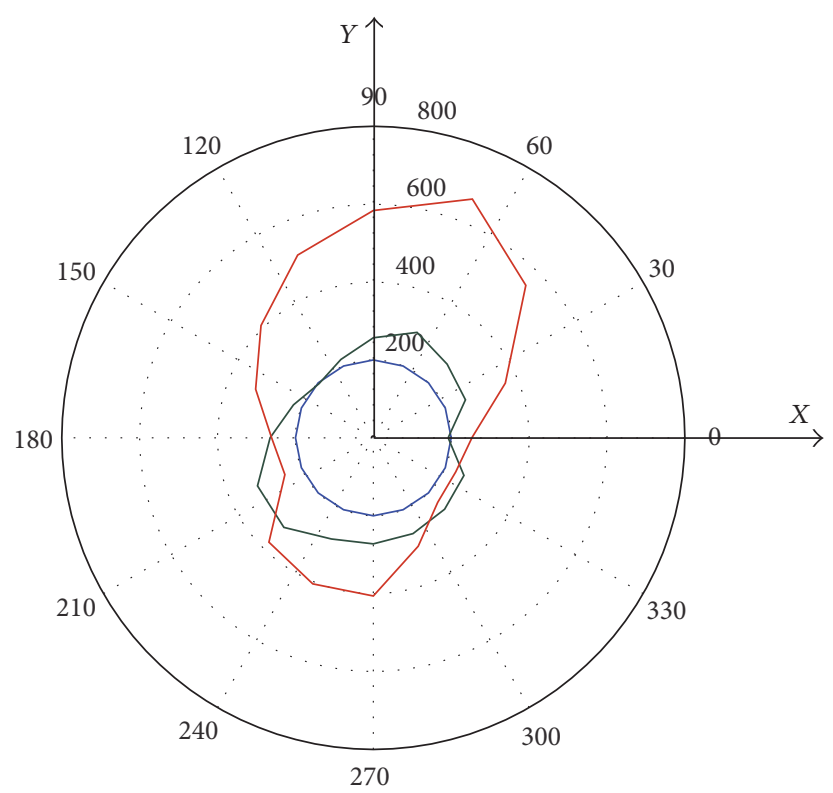

FIGURE 3: Pads clearances $(\mu \mathrm{m})$ in the upper journal bearing of a LHG: (a) nominal clearances (blue circle), (b) clearances measured at 0 MW (green closed curve), and (c) clearances measured at $700 \mathrm{MW}$ (red closed curve).

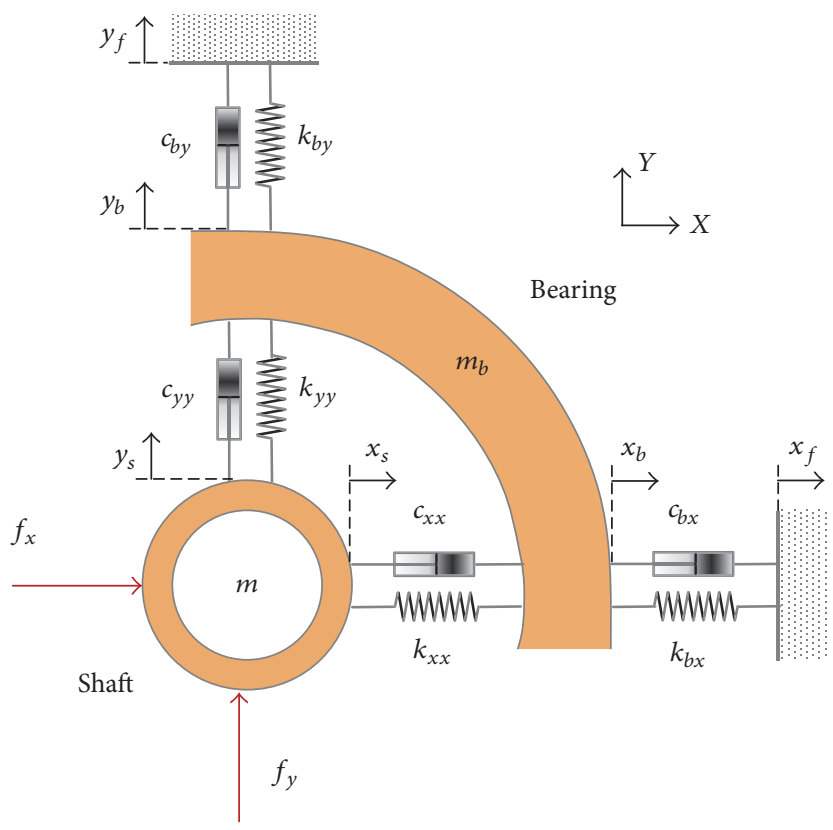

FIGURE 4: Simplified 2 DOF model for estimating journal bearing stiffness.

Direct oil film stiffnesses in $X$-direction and $Y$-direction are, respectively, $k_{x x}$ and $k_{y y}$, while direct damping coefficients are $c_{x x}$ and $c_{y y}$. Despite not being represented in Figure 4 , cross-coupled stiffnesses $\left(k_{x y}, k_{y x}\right)$ and damping $\left(c_{x y}, c_{y x}\right)$ coefficients are preliminarily considered. Stiffness and damping coefficients of the bearing bracket, in $X$ direction and $Y$-direction, are, respectively, given by $k_{b x}$ and $k_{b y}$ and $c_{b x}$ and $c_{b y}$. Lastly, shaft mass is $m$ and the effective mass of bearing bracket is $m_{b}$. As bearing brackets of LHG are isotropic $\left(k_{b x}=k_{b y}=k_{b} ; c_{b x}=c_{b y}=c_{b}\right)$, the bearing equations of motion are obtained as

$$
\begin{aligned}
& m_{b} \ddot{x}_{b}+c_{b} \dot{x}_{b}+k_{b} x_{b}=c_{x x} \dot{u}_{x}+c_{x y} \dot{u}_{y}+k_{x x} u_{x}+k_{x y} u_{y} \\
& m_{b} \ddot{y}_{b}+c_{b} \dot{y}_{b}+k_{b} y_{b}=c_{y x} \dot{u}_{x}+c_{y y} \dot{u}_{y}+k_{y x} u_{x}+k_{y y} u_{y} .
\end{aligned}
$$

It is well known that bracket damping may be neglected $\left(c_{b} \approx 0\right)$. Table 2 shows bearing bracket stiffnesses $\left(k_{2 x}, k_{2 y}\right.$, $k_{4 x}, k_{4 y}, k_{6 x}$, and $\left.k_{6 y}\right)$ and masses $\left(m_{1}, m_{2}, m_{3}\right)$. Using these 
values, one may verify that $k_{b} \gg m_{b} \Omega^{2}$, where $\Omega$ is the LHG angular frequency. Therefore, the former equations may be written in the frequency domain as

$$
\begin{aligned}
k_{b} X_{b}(i \Omega) \approx & \left(k_{x x}+i \Omega c_{x x}\right) U_{x}(i \Omega) \\
& +\left(k_{x y}+i \Omega c_{x y}\right) U_{y}(i \Omega) \\
k_{b} Y_{b}(i \Omega) \approx & \left(k_{y x}+i \Omega c_{y x}\right) U_{x}(i \Omega) \\
& +\left(k_{y y}+i \Omega c_{y y}\right) U_{y}(i \Omega),
\end{aligned}
$$

where $i$ is the imaginary number and the variables in uppercase are the power spectral density of the already described lowercase variables at the rotating speed. It is also well known that TPJB show negligible cross-coupling effects in normal operating conditions and that cross-coupled dynamic coefficients are much smaller than direct dynamic coefficients $\left(k_{m n} \ll k_{m m}\right.$ and $c_{m n} \ll c_{m m}$, with $\left.m \neq n\right)$ [12]. Therefore, for this type of bearing, the former equations may be expressed as

$$
\begin{aligned}
& k_{\text {eff } x x}=\frac{\left|X_{b}(j \Omega)\right|}{\left|U_{x}(j \Omega)\right|} k_{b}, \\
& k_{\text {eff } y y}=\frac{\left|Y_{b}(j \Omega)\right|}{\left|U_{y}(j \Omega)\right|} k_{b},
\end{aligned}
$$

where $k_{\text {eff } x x}=\left|k_{x x}+i \Omega c_{x x}\right|$ and $k_{\text {eff } y y}=\left|k_{y y}+i \Omega c_{y y}\right|$ are kinds of effective bearing stiffness, which include the effects of bearing damping. Experimental estimations [15] and theoretical calculations [20] indicate that damping effects are usually smaller than stiffness effects $\left(\Omega c_{x x}<k_{x x}\right.$ and $\Omega c_{y y}<k_{y y}$ ), but they are not negligible. The effective bearing stiffness is determined under the assumption of no cross-coupling effects $\left(k_{\text {eff } x y}=k_{\text {eff } y x}=0\right)$. In the former equations, $\left|U_{x}(i \Omega)\right|$ and $\left|U_{y}(i \Omega)\right|$ are the amplitudes of the once-per-turn shaft relative vibrations, respectively, in $X$-direction and $Y$-direction, while $\left|X_{b}(i \Omega)\right|$ and $\left|Y_{b}(i \Omega)\right|$ are the amplitudes of bearing absolute vibrations in the same frequency and directions. All these vibrations are expressed in displacement in adequate engineering units. Equation (5) may be used to experimentally determine and monitor the journal bearing effective stiffness.

\subsection{Method Validation}

2.2.1. Model to Simulate the Dynamic Behavior of LHG. Figure 5 shows a simplified model used to simulate the dynamic behavior of LHG. As these machines operate at subcritical speeds and as their shafts are much stiffer than their bearing brackets [10], the rotating part is considered a rigid body. It is supposed that shaft relative vibrations are low enough to model the journal bearings using linear stiffness and viscous damping (bearing damping coefficients are not shown in Figure 5 in order not to overload this figure). Bearing brackets are modeled as springs, with an effective mass equal to one-third of their total mass, as used by Cardinali [21], probably based on the effective mass of an oscillating spring [22]. This model considers the gyroscopic effect and the journal bearings anisotropy, including the cross-coupling effects in bearing stiffness. Figure 5 shows the two coordinate systems used to describe the LHG dynamics, an inertial system $(\mathbf{O} X, Y, Z)$ and a rotating system $(\mathbf{C} x, y, z)$. The LHG rotating part has a constant angular velocity $\Omega$ around $z$-axis (hydrogenerators operate synchronously with the electrical grid; then, the angle around $z$-axis is determined by $\varphi_{z}(t)=\varphi_{z}\left(t_{0}\right)+\Omega t$, where $t$ is time); it can make linear displacements in $X$-direction, $Y$-direction, and $Z$-direction besides angular oscillations around $X$-direction $\left(\varphi_{x}\right)$ and $Y$-direction $\left(\varphi_{y}\right)$. Bearing brackets effective masses can make linear displacements along the coordinates $x_{i}$ and $y_{i}(i=1$ for the upper journal bearing, $i=2$ for the lower journal bearing, and $i=3$ for the turbine journal bearing). Table 2 describes the main parameters of this model, in which values were obtained mostly in [10]. Bearing damping coefficients were considered proportional to bearing stiffness coefficients, that is, $c_{n i j}=\alpha k_{n i j}(n=1,3,5$ and $i, j=x, y)$, using $\alpha=0.0125 \mathrm{~s}$ estimated with basis in similar journal bearings [21].

As thrust bearing pads are evenly distributed and loaded, the axial displacement $Z$ may be decoupled from the other coordinates $[23,24]$. Once $\varphi_{z}$ is determined, the LHG dynamic behavior may be described by a 10 DOF model, represented by the following equation:

$$
\mathbf{M} \ddot{\mathbf{x}}+\mathbf{C} \dot{\mathbf{x}}+\Omega \mathbf{G} \dot{\mathbf{x}}+\mathbf{K} \mathbf{x}=\mathbf{F}(t) .
$$

In the former equation, $\mathbf{M}$ is the mass matrix, $\mathbf{C}$ is the damping matrix, $\Omega \mathbf{G}$ is the matrix of the gyroscopic effect, and $\mathbf{K}$ is the stiffness matrix. Also, $\mathbf{x}$ is the generalized coordinates vector and $\mathbf{F}(t)$ is the generalized forces vector.

The 10 DOF model given by (6) may be represented in the state space as follows:

$$
\begin{aligned}
\left\{\begin{array}{l}
\dot{\mathbf{x}}(t) \\
\ddot{\mathbf{x}}(t)
\end{array}\right\}= & {\left[\begin{array}{cc}
\mathbf{0} & \mathbf{I} \\
-\mathbf{M}^{-1} \mathbf{K} & -\mathbf{M}^{-1}(\mathbf{C}+\Omega \mathbf{G})
\end{array}\right]\left\{\begin{array}{l}
\mathbf{x}(t) \\
\dot{\mathbf{x}}(t)
\end{array}\right\} } \\
& +\left[\begin{array}{c}
\mathbf{0} \\
\mathbf{M}^{-1}
\end{array}\right] \mathbf{F}(t),
\end{aligned}
$$

where $\mathbf{0}$ is a square zero matrix and $\mathbf{I}$ is the identity matrix, both of order 10. The first four natural frequencies and the respective vibration modes obtained by using this simplified 10 DOF model showed a good agreement with the results obtained in simulations using a third-party software, based on the Finite Element Method (FEM), as well as with the results achieved by the LHG manufacturer, using the Transfer Matrix Method [10].

In the LHG used as references, the shaft relative vibrations are measured in two orthogonal directions of each journal bearing ( $X$ and $Y$ ), using $4 \mathrm{~V} / \mathrm{mm}$ proximity transducers of eddy current type and accuracy class of 5\%, installed in the ring support of the bearing pads, between two adjacent pads, where the shaft surface has better finishing. These vibrations are expressed in displacement, using micrometers $(\mu \mathrm{m})$ as engineering units. The bearing absolute vibrations are also measured in the same orthogonal directions using $1000 \mathrm{mV} / \mathrm{g}$ (this is practically the highest sensitivity for industrial piezoelectric accelerometers) industrial piezoelectric 
TABLE 2: Parameters of the rigid body model.

\begin{tabular}{|c|c|c|c|}
\hline Symbol & Description & Unit & Value \\
\hline$m$ & Mass of LHG rotating part & $\mathrm{kg}$ & $2.37 E 6$ \\
\hline$J_{p}$ & Polar moment of inertia LHG rotating part & $\mathrm{kgm}^{2}$ & $0.84 E 8$ \\
\hline$J_{d}$ & Diametral moment of inertia LHG rotating part & $\mathrm{kgm}^{2}$ & $1.09 E 8$ \\
\hline$m_{1}$ & Upper journal bearing (UJB) effective mass & $\mathrm{kg}$ & $0.45 E 5$ \\
\hline$m_{2}$ & Lower journal bearing (LJB) effective mass & $\mathrm{kg}$ & $1.00 E 5$ \\
\hline$m_{3}$ & Turbine journal bearing (TJB) effective mass & $\mathrm{kg}$ & $0.80 E 5$ \\
\hline$k_{1 x x}, k_{1 y y}$ & UJB bearing main stiffness & $\mathrm{N} / \mathrm{m}$ & $6.67 E 9$ \\
\hline$k_{1 x y}=k_{1 y x}$ & UJB bearing cross-coupling stiffness & $\mathrm{N} / \mathrm{m}$ & $0.00 E 9$ \\
\hline$k_{2 x}, k_{2 y}$ & UJB bracket stiffness & $\mathrm{N} / \mathrm{m}$ & $1.18 E 9$ \\
\hline$k_{3 x x}, k_{3 y y}$ & LJB bearing main stiffness & $\mathrm{N} / \mathrm{m}$ & $2.86 E 9$ \\
\hline$k_{3 x y}=k_{3 y x}$ & LJB bearing cross-coupling stiffness & $\mathrm{N} / \mathrm{m}$ & $0.00 E 9$ \\
\hline$k_{4 x}, k_{4 y}$ & LJB bracket stiffness & $\mathrm{N} / \mathrm{m}$ & $2.22 E 9$ \\
\hline$k_{5 x x}, k_{5 y y}$ & TJB bearing main stiffness & $\mathrm{N} / \mathrm{m}$ & $6.67 E 9$ \\
\hline$k_{5 x y}=k_{5 y x}$ & TJB bearing cross-coupling stiffness & $\mathrm{N} / \mathrm{m}$ & $0.00 E 9$ \\
\hline$k_{6 x}, k_{6 y}$ & TJB bracket stiffness & $\mathrm{N} / \mathrm{m}$ & $2.13 E 9$ \\
\hline$k_{7 x}, k_{7 y}$ & Generator magnetic stiffness & $\mathrm{N} / \mathrm{m}$ & $-0.60 E 9$ \\
\hline$k_{8}$ & Thrust bearing axial stiffness & $\mathrm{N} / \mathrm{m}$ & $19.4 E 9$ \\
\hline$k_{9 x}, k_{9 y}$ & Turbine seals effective stiffness & $\mathrm{N} / \mathrm{m}$ & $5.00 E 7$ \\
\hline$l_{0}$ & Distance center of mass, center of generator rotor & $\mathrm{m}$ & 2.328 \\
\hline$l_{1}$ & Distance center of mass, center of UJB & $\mathrm{m}$ & 5.433 \\
\hline$l_{2}$ & Distance center of mass, center of LJB & $\mathrm{m}$ & 0.088 \\
\hline$l_{3}$ & Distance center of mass, center of TJB & $\mathrm{m}$ & 8.767 \\
\hline$l_{4}$ & Distance center of mass, center of turbine rotor & $\mathrm{m}$ & 12.617 \\
\hline$\underline{l_{5}}$ & Distance center of mass, thrust bearing pivot & $\mathrm{m}$ & 2.113 \\
\hline
\end{tabular}

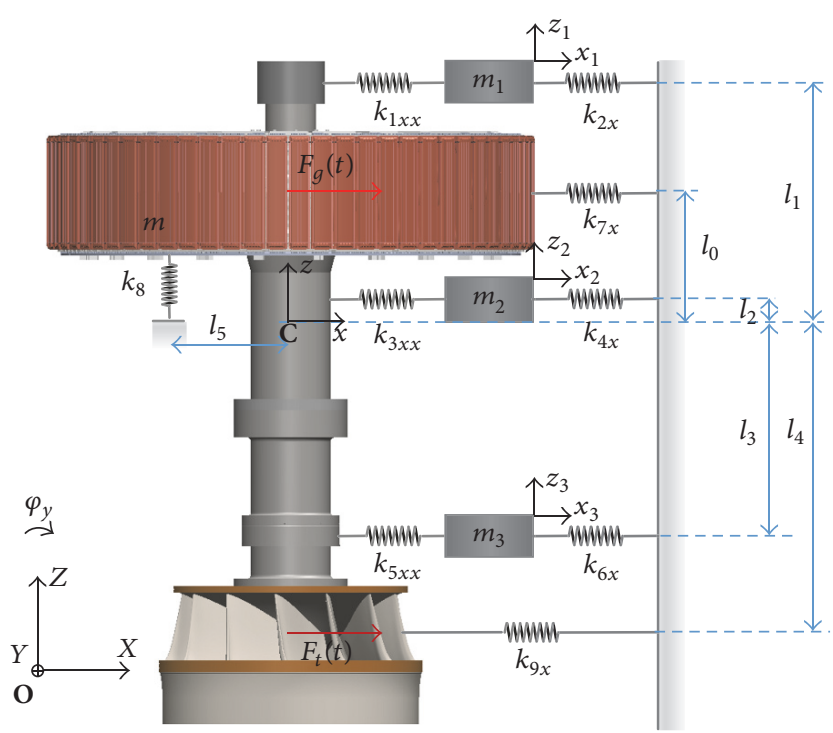

FIGURE 5: Simplified 10 DOF model to simulate LHG dynamic behavior.

accelerometers of accuracy class of $5 \%$ and with a lower cutoff frequency of $0.5 \mathrm{~Hz}$, installed in the same support of the proximity transducers. The acceleration signals were integrated by charge amplifiers for a better signal transmission. Therefore, bearing vibrations are expressed in velocity in millimeters per second ( $\mathrm{mm} / \mathrm{s})$. Table 3 shows the monitored shaft relative vibrations and bearing absolute vibrations, in the three journal bearings, expressed using the coordinates shown in Figure 5.

2.2.2. Validating the Method. A program was written in Matlab to solve state equation (7), using an output matrix that 
TABLE 3: Shaft relative vibrations measured by proximity transducers (in displacement) and bearing absolute vibrations measured by piezoelectric accelerometers and integrated by charge amplifiers (in velocity).

\begin{tabular}{lcccc}
\hline \multirow{2}{*}{ Journal bearing } & \multicolumn{2}{c}{ Shaft relative vibrations } & \multicolumn{2}{c}{ Bearing absolute vibrations } \\
& $X$-direction & $Y$-direction & $X$-direction & $\dot{x}_{1}$ \\
\hline Upper bearing & $X+l_{1} \varphi_{y}-x_{1}$ & $Y-l_{1} \varphi_{x}-y_{1}$ & $\dot{y}_{1}$ & $\dot{x}_{2}$ \\
Lower bearing & $X+l_{2} \varphi_{y}-x_{2}$ & $Y-l_{2} \varphi_{x}-y_{2}$ & $\dot{y}_{2}$ \\
Turbine bearing & $X-l_{3} \varphi_{y}-x_{3}$ & $Y+l_{3} \varphi_{x}-y_{3}$ & $\dot{x}_{3}$ & $\dot{y}_{3}$ \\
\hline
\end{tabular}

TABLE 4: Original and estimated bearing effective stiffnesses of the upper journal bearing $\left(\mathbf{k}_{\mathbf{2}}=\mathbf{k}_{2 \mathbf{y}}=1.18 \mathrm{GN} / \mathrm{m}\right)$ of a $700 \mathrm{MW}$ hydrogenerator, using synthesized shaft and bearing vibration signals.

\begin{tabular}{lccccccccc}
\hline Condition & \multicolumn{3}{c}{$\begin{array}{c}\text { Original bearing stiffnesses } \\
{[\mathrm{GN} / \mathrm{m}]}\end{array}$} & \multicolumn{2}{c}{$\begin{array}{c}\text { Simulated shaft } \\
\text { vibrations }[\mu \mathrm{m}]\end{array}$} & \multicolumn{2}{c}{$\begin{array}{c}\text { Simulated bearing } \\
\text { vibrations }[\mu \mathrm{m}]\end{array}$} & \multicolumn{2}{c}{$\begin{array}{c}\text { Estimated effective } \\
\text { stiffnesses }[\mathrm{GN} / \mathrm{m}]\end{array}$} \\
& $k_{1 x x}$ & $k_{1 x y}, k_{1 y x}$ & $k_{1 y y}$ & $\left|U_{x}(j \Omega)\right|$ & $\left|U_{y}(j \Omega)\right|$ & $\left|X_{b}(j \Omega)\right|$ & $\left|Y_{b}(j \Omega)\right|$ & $k_{\text {eff } x x}$ & $k_{\text {eff } y y}$ \\
\hline 1 & 6.67 & 0.00 & 6.67 & 4.3 & 4.3 & 24.5 & 24.5 & 6.72 \\
2 & 3.33 & 0.00 & 3.33 & 9.3 & 9.3 & 26.5 & 26.4 & 3.36 & 3.35 \\
3 & 1.11 & 0.00 & 1.11 & 30.6 & 30.3 & 29.1 & 28.8 & 1.12 & 1.12 \\
4 & 3.33 & -0.33 & 1.11 & 9.7 & 32.5 & 26.1 & 29.5 & 3.18 & 1.07 \\
5 & 3.33 & -0.66 & 3.33 & 9.7 & 10.2 & 26.5 & 26.7 & 3.22 & 3.09 \\
\hline
\end{tabular}

gives the twelve vibration signals listed in Table 3 in the output vector, avoiding numerical differentiations or integrations of the obtained signals. The LHG vibration signals were obtained using the nominal parameters shown in Table 2 but varying the upper journal bearing stiffness and lower journal bearing stiffness, as described in Tables 4 and 5. For simplicity, it was assumed that the upper bearing stiffness and the lower bearing stiffness varied proportionally in different conditions: isotropic and anisotropic bearings with and without cross-coupling effects.

An unbalance ISO quality grade G4.25 in the generator rotor was used as excitation. A white Gaussian noise was added to simulate the effects of hydraulic excitations in the rotating part, producing a signal-to-noise ratio of $10 \mathrm{~dB}$ in relation to the unbalance force. It was considered that the generator was not excited $\left(k_{7 x}=k_{7 y}=0\right)$. The LHG vibration signals synthesized by the model were processed to obtain the amplitudes of shaft $\left(\left|U_{x}(j \Omega)\right|\right.$ and $\left.\left|U_{y}(j \Omega)\right|\right)$ and bearing $\left(\left|X_{b}(j \Omega)\right|\right.$ and $\left.\left|Y_{b}(j \Omega)\right|\right)$ vibrations at the rotating speed. These descriptors were used in (5), together with bracket stiffnesses, to estimate the effective journal bearing stiffnesses. The results are shown in Tables 4 and 5 .

The estimated bearing effective stiffness of the upper journal bearing and that of the lower journal bearing were used back in the LHG model described in the former section. The vibration signals obtained with the estimated stiffnesses are displayed in Tables 6 and 7, together with the errors in relation to the original vibrations, shown in Tables 4 and 5. It may be seen that the maximum error is lower than $3 \%$, which validates the method for experimentally estimating journal bearing stiffness.

\section{Estimation of Bearings Stiffnesses of a 700 MW Hydrogenerator}

This section shows the application of the described method in the estimation of the journal bearings stiffnesses of a $700 \mathrm{MW}$ hydrogenerator by the reprocessing of the vibration signals recorded during the generator rotor balancing and during the hydraulic stability tests.

3.1. Using the Generator Rotor Unbalance as Excitation. Figure 6 shows the shaft relative and the bearing absolute vibrations measured in $X$-direction of the upper journal bearing of a $700 \mathrm{MW}$ hydrogenerator, operating at speed-no-load in steady-state condition, during the balancing of the generator rotor, when this rotor had unbalance ISO quality grade G4.25. The hydrogenerator had been just assembled and the indexes regarding the shaft static runout, the shaft verticality, and the shaft alignment were all lower than the tolerances of the used standard [25]. Figure 7 shows the same signals but measured on the lower journal bearing. On both figures, the upper diagrams show the vibration signals in time domain, acquired with a sampling frequency of $600 \mathrm{~Hz}$. The lower diagrams show Welch's power spectral density estimate of these signals, obtained using a Hann window with 8192 points, with an overlap of $12.5 \%$. Shaft vibrations spectra are shown in displacement, in 0 to peak values, expressed in micrometers $\left(\mu \mathrm{m}_{p}\right)$. Bearing vibrations are shown in velocity, also in 0 to peak values, expressed in millimeters per second $\left(\mathrm{mm} / \mathrm{s}_{p}\right)$.

The effective stiffnesses in $X$-directions of the upper journal bearing and the lower journal bearing may be estimated by means of (5), using the amplitudes of shaft relative 
TABLE 5: Original and estimated bearing effective stiffnesses of the lower journal bearing $\left(\mathbf{k}_{\mathbf{4} \mathbf{x}}=\mathbf{k}_{\mathbf{4 y}}=2.22 \mathrm{GN} / \mathrm{m}\right)$ of a $700 \mathrm{MW}$ hydrogenerator, using synthesized shaft and bearing vibration signals.

\begin{tabular}{lccccccccc}
\hline Condition & \multicolumn{3}{c}{$\begin{array}{c}\text { Original bearing stiffness } \\
{[\mathrm{GN} / \mathrm{m}]}\end{array}$} & \multicolumn{3}{c}{$\begin{array}{c}\text { Simulated shaft } \\
\text { vibrations }[\mu \mathrm{m}]\end{array}$} & \multicolumn{2}{c}{$\begin{array}{c}\text { Simulated bearing } \\
\text { vibrations }[\mu \mathrm{m}]\end{array}$} & \multicolumn{2}{c}{$\begin{array}{c}\text { Estimated effective } \\
\text { stiffness }[\mathrm{GN} / \mathrm{m}]\end{array}$} \\
\hline 1 & $k_{1 x x}$ & $k_{1 x y}, k_{1 y x}$ & $k_{1 y y}$ & $\left|U_{x}(j \Omega)\right|$ & $\left|U_{y}(j \Omega)\right|$ & $\left|X_{b}(j \Omega)\right|$ & $\left|Y_{b}(j \Omega)\right|$ & $k_{\text {eff } x x}$ & $k_{\text {eff } y y}$ \\
2 & 2.86 & 0.00 & 2.86 & 10.0 & 10.1 & 13.1 & 13.2 & 2.91 \\
3 & 1.43 & 0.00 & 1.43 & 17.2 & 17.1 & 11.2 & 11.2 & 1.45 & 1.2 \\
4 & 0.48 & 0.00 & 0.48 & 36.9 & 37.1 & 7.9 & 7.9 & 0.48 & 0.47 \\
5 & 1.43 & -0.14 & 0.48 & 17.2 & 38.4 & 11.1 & 7.9 & 1.43 & 0.46 \\
\hline
\end{tabular}

TABLE 6: Simulated shaft and bearing vibrations at the upper journal bearing, using the estimated bearing effective stiffnesses, including the errors in comparison to the vibrations shown in Table 4.

\begin{tabular}{|c|c|c|c|c|c|c|c|c|}
\hline \multirow{2}{*}{ Condition } & \multicolumn{4}{|c|}{ Simulated shaft vibrations $[\mu \mathrm{m}]$} & \multicolumn{4}{|c|}{ Simulated bearing vibrations $[\mu \mathrm{m}]$} \\
\hline & $\left|U_{x}(j \Omega)\right|$ & Error $[\%]$ & $\left|U_{y}(j \Omega)\right|$ & Error $[\%]$ & $\left|X_{b}(j \Omega)\right|$ & Error [\%] & $\left|Y_{b}(j \Omega)\right|$ & Error [\%] \\
\hline 1 & 4.2 & -2.3 & 4.3 & 0.0 & 24.4 & -0.4 & 24.5 & 0.0 \\
\hline 2 & 9.2 & -1.1 & 9.2 & -1.1 & 26.5 & 0.0 & 26.5 & 0.4 \\
\hline 3 & 30.0 & -2.0 & 30.2 & -0.3 & 29.0 & 0.3 & 29.0 & 0.7 \\
\hline 4 & 9.5 & -2.1 & 32.2 & -0.9 & 25.9 & -0.8 & 29.5 & 0.0 \\
\hline 5 & 9.6 & -1.0 & 10.1 & -1.0 & 26.4 & -0.4 & 26.7 & 0.0 \\
\hline
\end{tabular}

and bearing absolute vibrations at the rotating frequency, measured in the frequency spectra shown in Figures 6 and 7. Using the brackets stiffnesses shown in Table $2\left(k_{2 x}=\right.$ $1.18 \mathrm{GN} / \mathrm{m}$ and $\left.k_{4 x}=2.22 \mathrm{GN} / \mathrm{m}\right)$, the estimated stiffness is $k_{\text {eff } 1 x x}=0.69 \mathrm{GN} / \mathrm{m}$ for the upper journal bearing and $k_{\text {eff } 3 x x}=0.37 \mathrm{GN} / \mathrm{m}$ for the lower journal bearing. This procedure was repeated by the reprocessing of nine sets of vibration signals recorded during the three-day balancing process of the generator rotor. In the first day, the rotor was unbalanced with grade G6.65. In the second day, the rotor had a calibration weight and was unbalanced with grade G4.25. In the third day, the rotor was balanced. Tables 8 and 9 show, respectively, the estimated effective stiffness of the upper journal bearing and that of the lower journal bearing. These tables also show the relative time of the signals acquisition, the amplitudes of the shaft relative and bearing absolute vibrations at the rotating speed $(1 \times$ vibrations $)$ in $X$-direction and $Y$-direction, and the gap (the gaps of the proximity transducers are determined by the average value of the shaft relative vibrations. The coordinates of the two orthogonal gaps ( $X$-direction and $Y$-direction) are related to the coordinates of the shaft center or the shaft eccentricity, with the interference of thermal expansions of shaft collar, bearing housing, and proximity transducers support) of the proximity transducers.

Table 8 shows that shaft vibrations in $Y$-direction of the upper journal bearing are higher than those in $X$-direction, indicating a small anisotropy in this bearing. Table 9 shows that shaft vibrations have similar amplitude in these two orthogonal directions, indicating that the lower journal bearing is practically isotropic. Figure 8 shows the corresponding filtered shaft orbits in these journal bearings. This behavior agrees with the results of the bearing special tests [19], which indicated that the lower bearing is less susceptible to the thermal dimensional changes that occur in the upper bearing (see Figure 3). These tests indicated no evidence of thermal bow in the shaft.

Tables 8 and 9 also show the reduction of shaft relative vibrations during the transient process of the warming up of both bearings. For instance, in the second day, the shaft relative vibrations of both bearings decreased practically to the half of their initial values after seven hours of operation. This reduction is caused by bearing stiffness increasing, which results from the balance of three processes that occur during bearing warming. The first process is the decreasing of the lubricant viscosity, a process that reduces bearing stiffness (the pivot stiffness is much higher than the bearing stiffness; consequently, the viscosity of the oil film has low influence on the pad clearance). The second process, the clearance reduction due to shaft collar differential thermal expansion, acts in the opposite way. The third process is the changing in shaft eccentricity, which may increase or decrease bearing stiffness. This last process may be significantly affected by the uneven pad clearances distribution due to bearing housing deformation, as shown in Figure 3.

Figure 9 shows the points obtained with the transducers gaps during the generator rotor balancing, similarly to Figure 2. During this process, the hydrogenerator was operating at speed-no-load condition. Theoretically, the static radial loads on the journal bearings are negligible in this operating condition, as there was no magnetic pull and as the hydraulic pull was minimum. The significant apparent changes of shaft eccentricity, along straight lines with similar directions in the three journal bearings, may be partially explained by thermal expansions of shafts collars and thrust block. However, there is also a shaft displacement, detected when comparing the clearances at steady state (-G6.65, +G4.25, and $\square$ Balan). The separation between the real shaft displacements and the 
TABLE 7: Simulated shaft and bearing vibrations at the lower journal bearing, using the estimated bearing effective stiffnesses, including the errors in comparison to the vibrations shown in Table 5.

\begin{tabular}{lcccccccc}
\hline \multirow{2}{*}{ Condition } & \multicolumn{3}{c}{ Simulated shaft vibrations $[\mu \mathrm{m}]$} & \multicolumn{3}{c}{ Simulated bearing vibrations $[\mu \mathrm{m}]$} \\
& $\left|U_{x}(j \Omega)\right|$ & Error $[\%]$ & $\mid U_{y}(j \Omega)$ & Error $[\%]$ & $\left|X_{b}(j \Omega)\right|$ & Error $[\%]$ & $\left|Y_{b}(j \Omega)\right|$ & Error $[\%]$ \\
\hline 1 & 9.9 & -1.0 & 10.0 & -1.0 & 13.2 & 0.8 & 13.2 \\
2 & 17.0 & -1.2 & 17.0 & -0.6 & 11.2 & 0.0 & 11.2 \\
3 & 36.5 & -1.1 & 36.8 & -0.8 & 8.0 & 1.3 & 7.9 \\
4 & 17.1 & -0.6 & 38.0 & -1.0 & 11.2 & 0.9 & 8.0 & 0.0 \\
5 & 17.2 & -1.1 & 17.9 & -0.6 & 11.2 & 0.0 & 11.1 \\
\hline
\end{tabular}

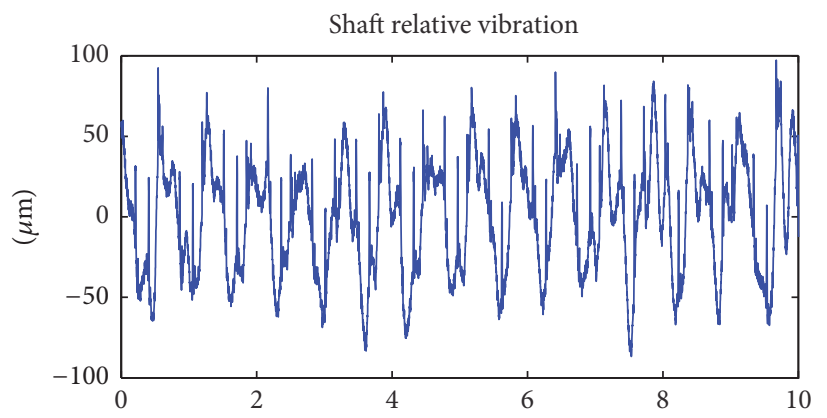

(s)

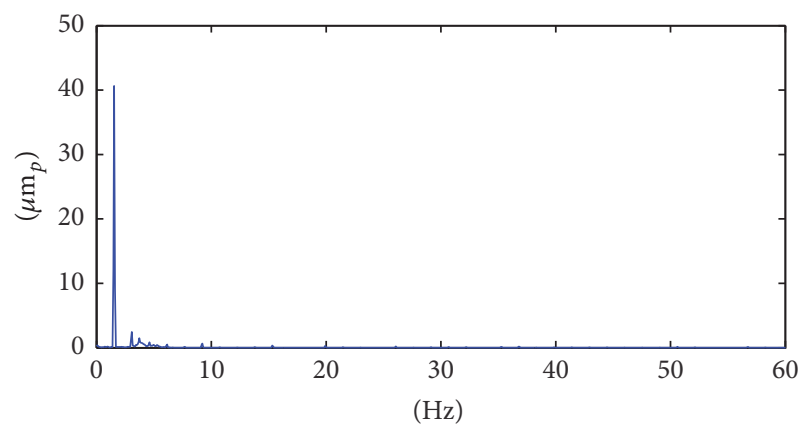

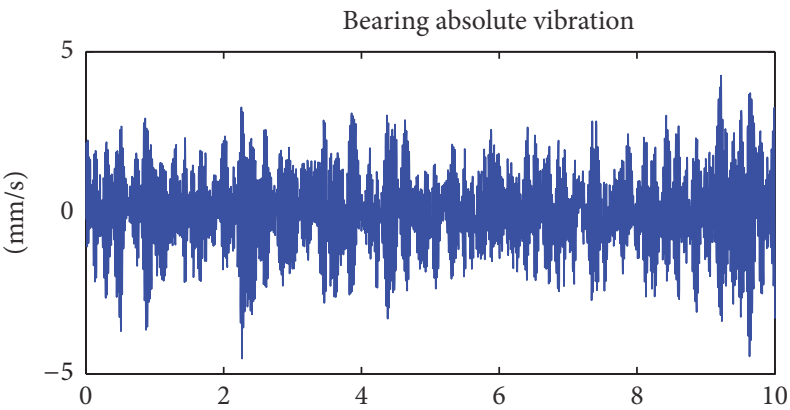

$(\mathrm{s})$

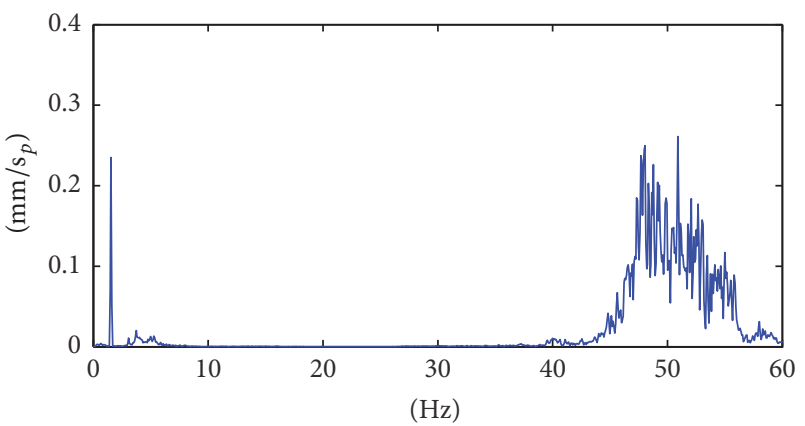

FIGURE 6: Shaft relative and bearing absolute vibrations at $\mathbf{X}$-direction of the upper journal bearing when generator rotor had unbalance G4.25 at the relative time $\mathbf{t}_{1}+7.0 \mathrm{~h}$.

apparent shaft displacements, originated by the clearance decreasing due to thermal effects, may be done duplicating the number of measurements, using four proximity transducers per journal bearing [17].

Table 8 shows that, after 6.5 hours of operation, in the second day and in the third day, the gaps of both proximity transducers of the upper journal bearing decreased approximately $150 \mu \mathrm{m}$. Table 9 shows that the gap reduction in the lower journal bearing was $210 \mu \mathrm{m}$ in the second day and $350 \mu \mathrm{m}$ in the third day. In all measurements, the gaps varied in the same way; their values decreased in similar amounts in both $X$-direction and $Y$-direction. As the proximity transducers are practically fixed in the ring that holds bearing pads, using support of small dimensions, the variations in the transducers gaps are mainly due to differential thermal expansion of shaft collars and due to changes in shaft eccentricity. Whatever is the proportion of these two possibilities, these changes indicate significant and little predictable variations in the bearing clearances during thermal transients. This is another example of the difficulties in determining bearing operating conditions accurately [11]. However, these changes may be estimated with a satisfactory accuracy in monitoring activities, even in the presence of bearing symmetrical deformations, if suitable transducers arrangements are used [17].

The bearing absolute vibrations have a different behavior. Table 8 indicates that measurements of bearing absolute vibrations in $Y$-direction of the upper journal bearing were not reliable and they were neglected. Table 9 indicates that the vibration level in $Y$-direction of the lower journal bearing is at least five times higher than the vibration level in $X$-direction. This degree of anisotropy is suspicious and it could be related to the difficulties in measuring low amplitude vibrations at low frequencies, using piezoelectric accelerometers. This subject is discussed in Section 3.3.

Considering only the estimates obtained with the generator rotor unbalanced, disregarding those estimated using bearing vibrations with low amplitudes, Table 8 shows that the average bearing stiffness of the upper journal bearing is $0.48 \mathrm{GN} / \mathrm{m}$ in $X$-direction. Table 9 shows that the average 


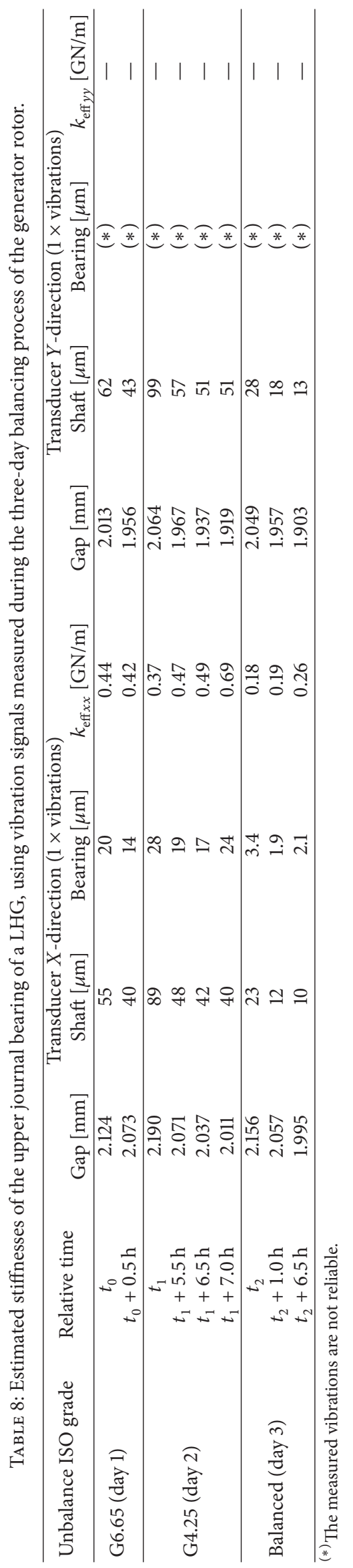




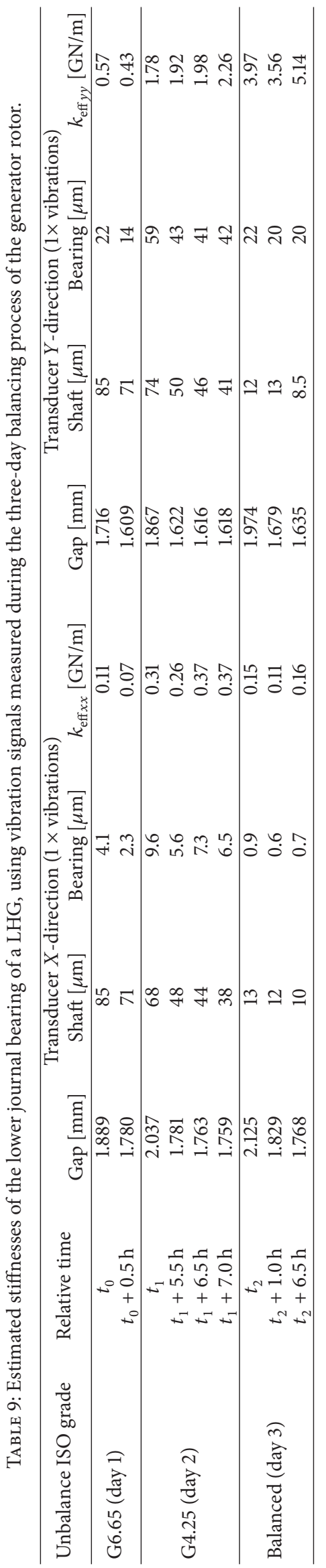




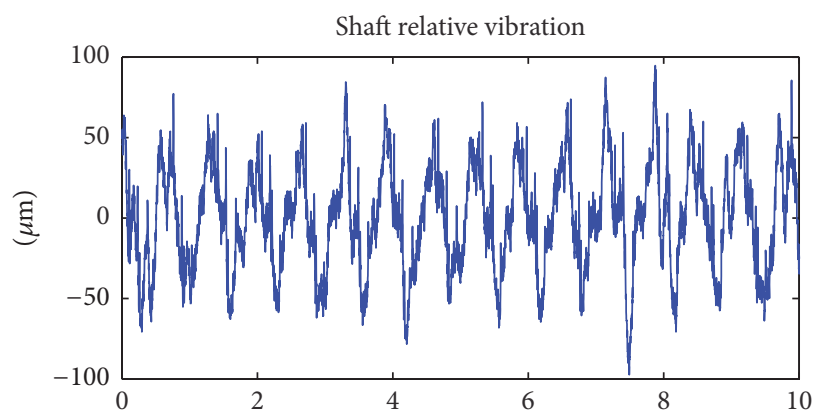

(s)

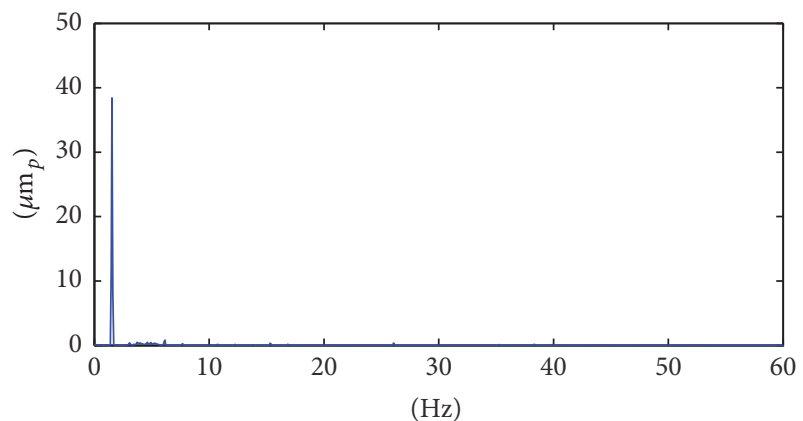

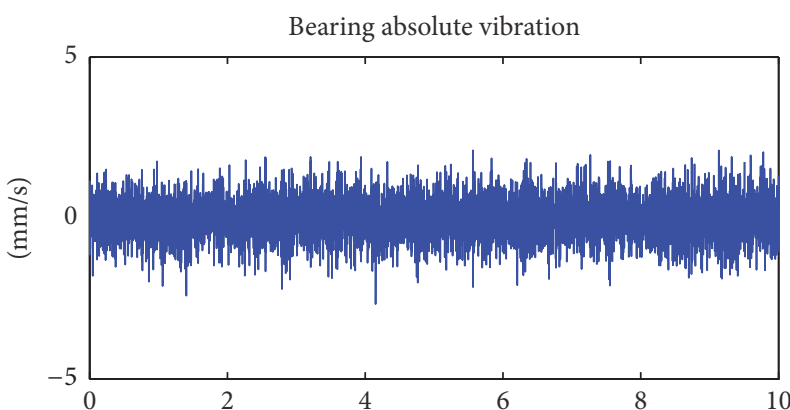

(s)

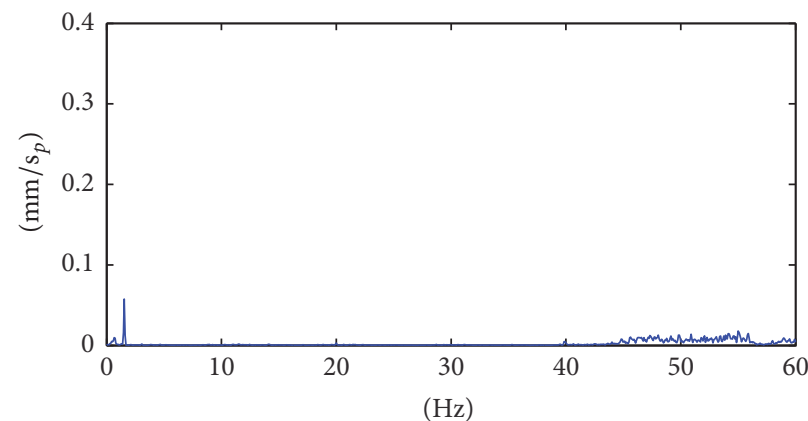

FIGURE 7: Shaft relative and bearing absolute vibrations at $\mathbf{X}$-direction of the lower journal bearing when generator rotor had unbalance G4.25 at the relative time $\mathbf{t}_{1}+7.0 \mathrm{~h}$.

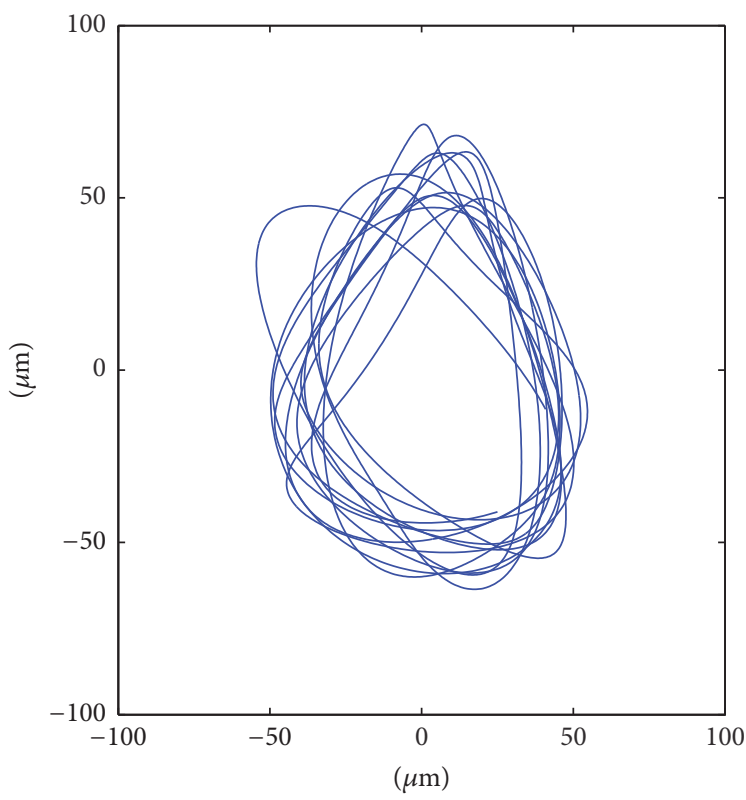

(a)

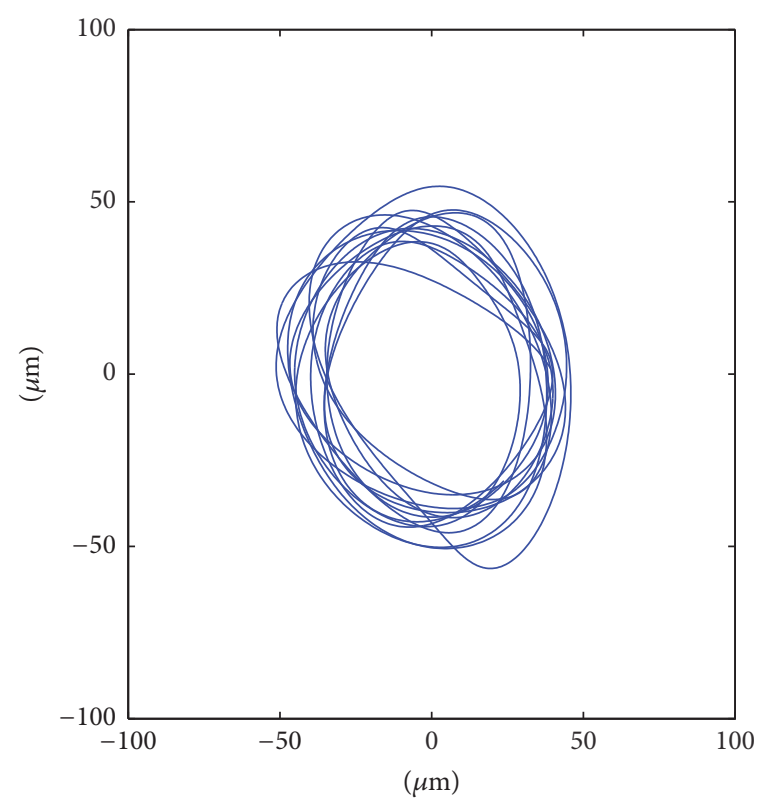

(b)

FIGURE 8: Filtered shaft orbits in the upper journal bearing (a) and lower journal bearing (b) when generator rotor had unbalance G4.25 at the relative time $\mathbf{t}_{1}+7.0 \mathrm{~h}$.

bearing stiffness of the lower journal bearing is similar $(0.50 \mathrm{GN} / \mathrm{m}$ in $Y$-direction), when unbalance level is G6.65. These values are one order of magnitude lower than the bearing direct stiffnesses determined by the LHG manufacturer at the design phase (the hydrogenerator manufacturer determined bearing stiffnesses using a hydrodynamic model, solving Reynolds equation using the Finite Difference Method. The authors confirmed these values using an independent calculation), which are described in Tables 1 and 2. However, when the unbalance level is reduced to G4.25, 

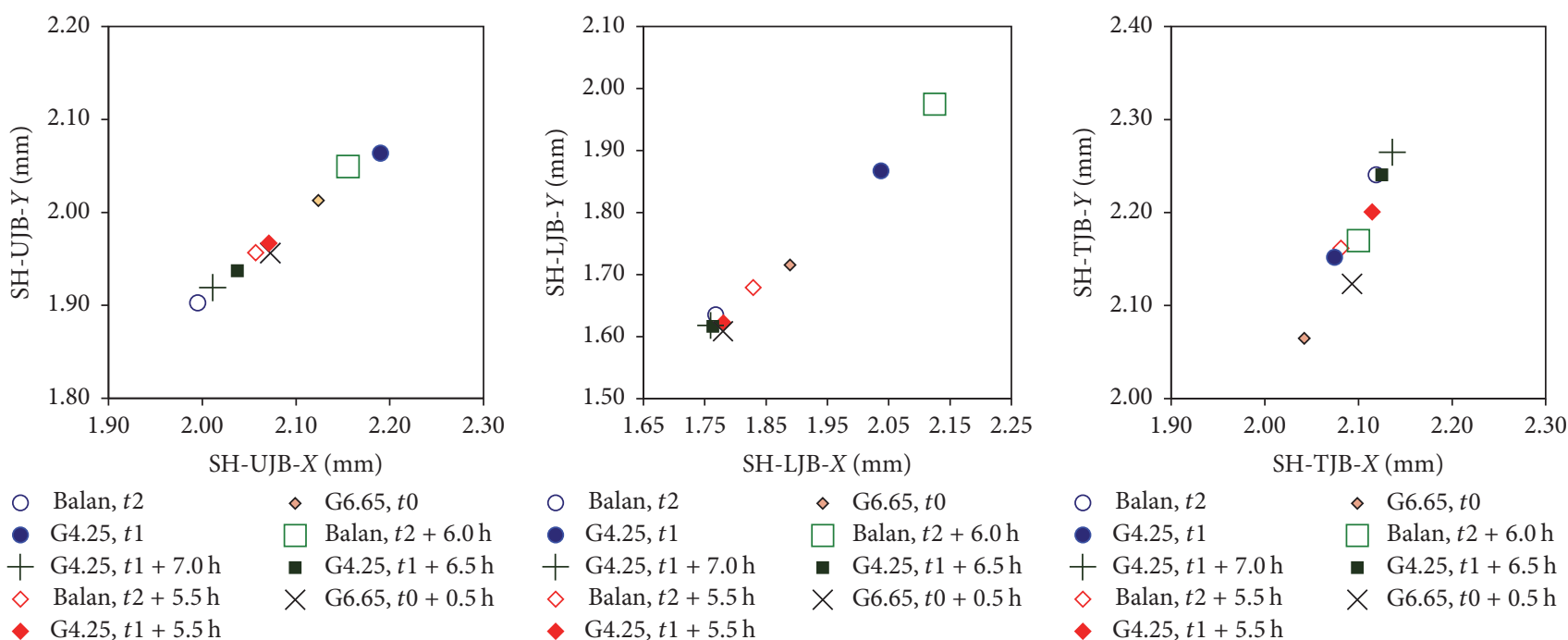
- Balan, $t 2$
- $\mathrm{G} 4.25, t 1$
+ G4.25, $t 1+7.0 \mathrm{~h}$
$\diamond$ Balan, $t 2+5.5 \mathrm{~h}$
$-\mathrm{G} 4.25, t 1+5.5 \mathrm{~h}$
$\diamond \mathrm{G6} 65, t 0$
$\square$ Balan, $t 2+6.0 \mathrm{~h}$
- G4.25, $t 1+6.5 \mathrm{~h}$
$\times \mathrm{G} 6.65, t 0+0.5 \mathrm{~h}$

FIGURE 9: Shaft eccentricity in the upper, lower, and turbine journal bearings of a LHG at speed-no-load condition, with the generator rotor balanced (Balan) and unbalanced, with ISO quality grades G4.25 and G6.65.

the average stiffness of the lower journal bearing increased in about four times, probably due to changes in the shaft eccentricity mentioned previously.

3.2. Using Partial Load Vortices as Excitations. Tables 8 and 9 show that when the generator rotor is balanced, the shaft relative and the bearing absolute vibrations cannot be measured at the rotating speed with an adequate accuracy. The artificial generation of an unbalance in the generator rotor or in the turbine rotor is not feasible, it is time-consuming, and it implies financial losses, exactly what one wants to avoid by using vibration-based condition monitoring. An alternative excitation is the force produced by the vortices that are produced in a Francis turbine when the LHG operates at partial load. Figures 10 and 11 show the shaft relative and bearing absolute vibrations in the upper and lower journal bearings regarding the order of the harmonic component, when a LHG operates at $320 \mathrm{MW}$. In this range, vibrations occur mainly at a quarter of the rotating speed $(0.35 \mathrm{~Hz})$. Shaft relative vibrations are 68 and $110 \mu \mathrm{m}$, respectively, in the upper and in the lower journal bearings. The bearing absolute vibrations are 8.9 and $16.8 \mu \mathrm{m}$ in the same order.

Using the process described in the previous section, the generator journal bearing stiffnesses are $k_{\text {eff } 1 x x}=0.29 \mathrm{GN} / \mathrm{m}$ and $k_{\text {eff } 3 x x}=0.18 \mathrm{GN} / \mathrm{m}$. These values are similar to the results obtained at the rotating speed after the rotor balancing (see Tables 8 and 9). This alternative excitation is easily applicable in hydrogenerators driven by Francis turbines. However, this method will not work properly in the case of Kaplan turbines due to the good hydraulic performance of this type of turbine when operating in partial load. Moreover, the concept of bearing stiffness must be extended when using this excitation, once the amplitude of shaft vibrations reaches $40 \%$ of the bearing nominal clearance. In addition, as the excitation frequency was reduced, the problems in measuring low frequency low amplitude vibrations using piezoelectric accelerometers have become worse. Anyway, this is probably the only practical method to estimate bearing stiffness with the large hydrogenerator in operation. This procedure may be improved by using more suitable transducers to measure shaft relative and bearing absolute vibrations, as well as by using more samples with increased sampling time and common signal analysis tools, such as synchronous averaging.

\subsection{Further Discussions on the Results}

3.3.1. Discussion about the Method's Uncertainty. The estimation method involves the shaft relative and the bearing absolute vibrations besides the bracket stiffness. The discussion about the method's uncertainty should begin with the accuracy class of the transducers used to measure these vibrations, $5 \%$ for both proximity transducers and piezoelectric accelerometers. This is a good accuracy class for industrial vibration transducers, but it must be verified before installation. The sensitivity of proximity transducers is easily verified by standard static calibrations, but the confirmation of the sensitivity of piezoelectric accelerometers in the low frequency range $(0.35$ to $2.0 \mathrm{~Hz}$ ) is not trivial.

Both shaft electrical runout and shaft mechanical runout may have significant influence on the uncertainty of shaft relative vibration at the rotating speed, especially in the case of low amplitude vibrations. Shaft mechanical runout may originate real bearing absolute vibrations, which will cause additional uncertainty. Shaft runout effects may be usually estimated and mitigated by subtracting the unfiltered vibration signal sampled at slow roll speed from the signal measured at the nominal rotating speed [26]. However, this method is not applicable to LHG due to the poor performance of TPJB at low speeds. Also, due to the natural difficulties created by the large dimensions involved, shaft collar demagnetizing, burnishing, or coating is not applicable [27]. As it uses a frequency different from the rotating speed, the alternative excitation proposed in Section 3.2 has also the advantage of mitigating runout errors. 


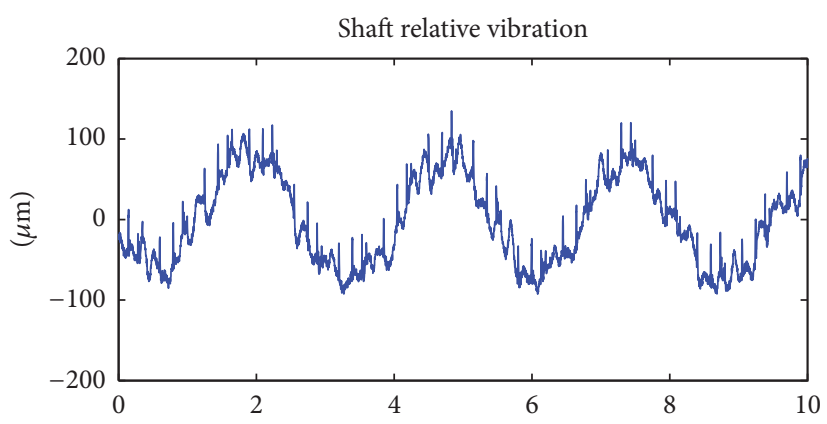

$(s)$

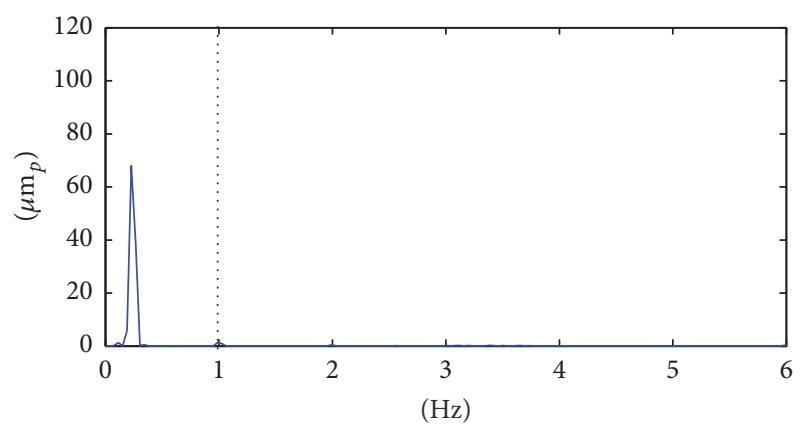

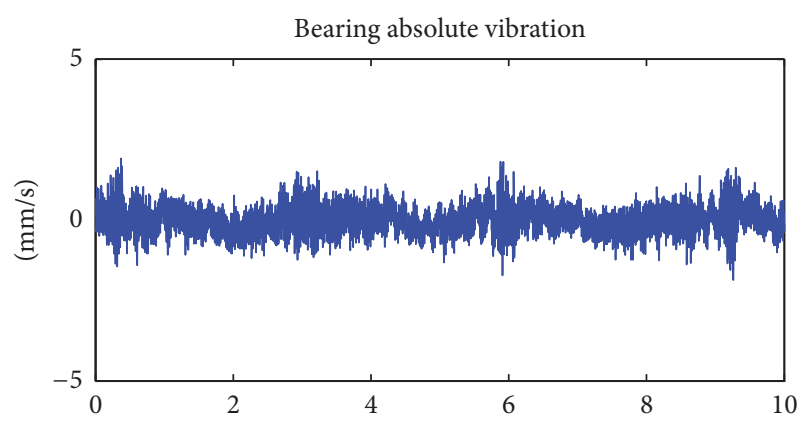

(s)

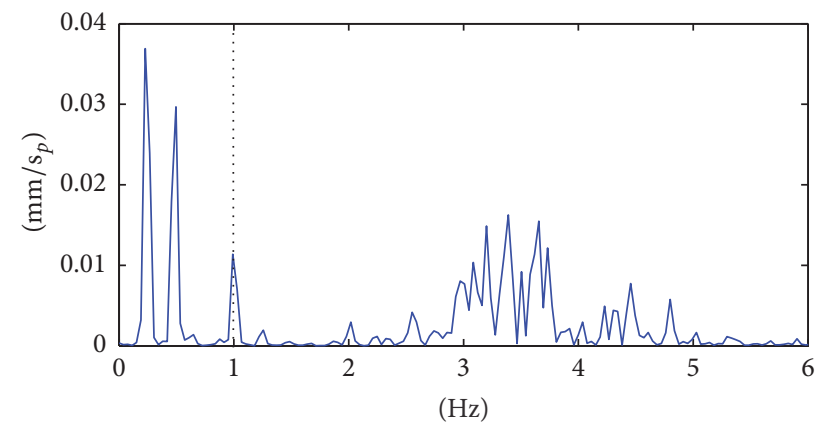

FIGURE 10: Shaft relative and bearing absolute vibrations at $\mathbf{X}$-direction of the upper journal bearing, with a balanced generator rotor operating with $320 \mathrm{MW}$.

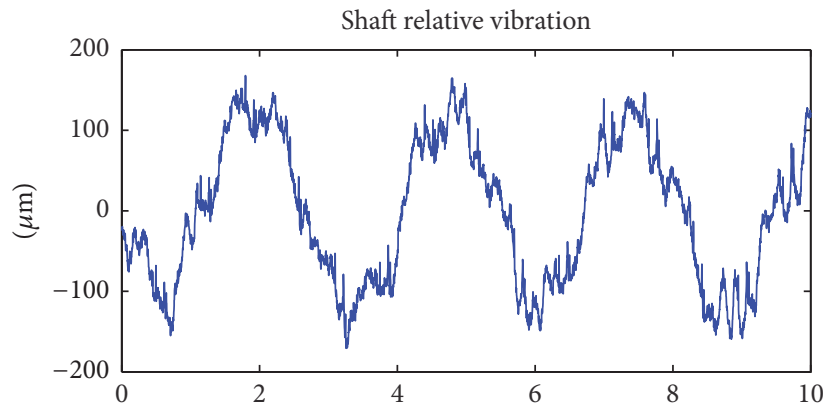

(s)

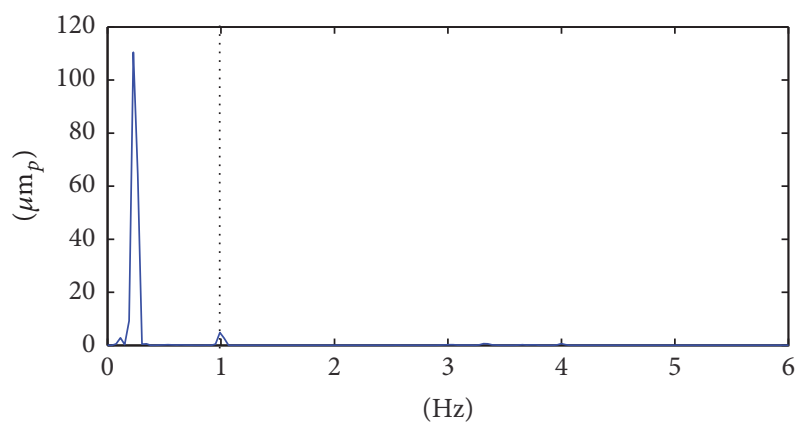

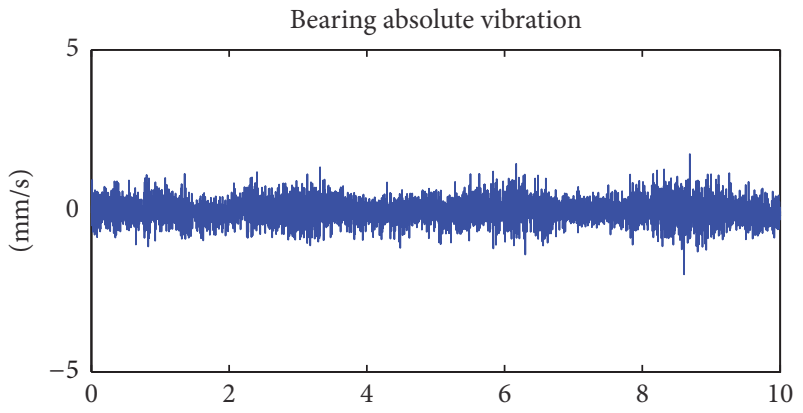

(s)

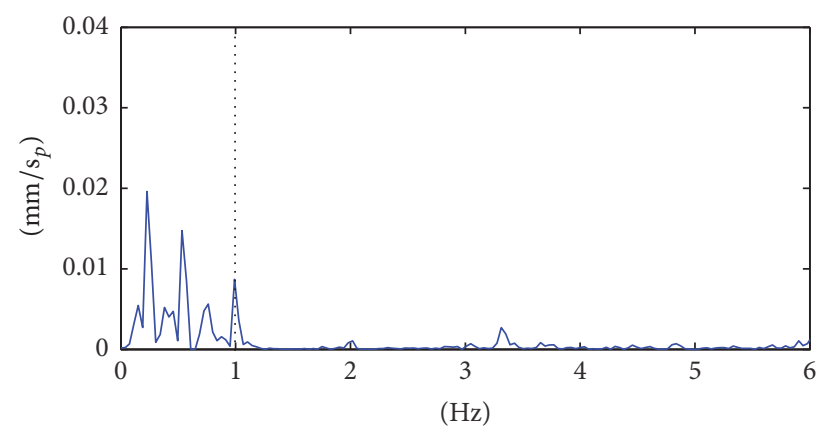

FIGURE 11: Shaft relative and bearing absolute vibrations at $\mathbf{X}$-direction of the lower journal bearing, with a balanced generator rotor operating with 320 MW.

The use of piezoelectric accelerometers creates additional uncertainties in the measured bearing absolute vibrations. Table 9 indicates that the highest amplitude at rotating speed $(92.3 \mathrm{r} / \mathrm{min})$ is about $60 \mu \mathrm{m}$, a vibration that generates a signal of approximately $0.6 \mathrm{mV}$ in the output of an accelerometer with sensitivity of $1000 \mathrm{mV} / \mathrm{g}$. This problem becomes worse when using the partial load vortices as excitation due to the frequency reduction to a quarter of the rotating speed. The 
acquisition and processing of such low voltage signals require special care, particularly in a noisy environment like a power plant.

As alternative, there are velocity transducers of high sensitivity $(50 \mathrm{mV} / \mathrm{mm} / \mathrm{s})$, equipped with a signal conditioner that electronically extends the lower cutoff frequency $(-3 \mathrm{~dB})$ down to $1 \mathrm{~Hz}$ or $0.5 \mathrm{~Hz}$. Theoretically, the voltage generated by these transducers, for the same bearing vibration, is fifty times higher than that produced by the accelerometer previously described, which allows better signal handling. However, the datasheet of some of these transducers shows considerable fluctuations in their sensitivity at the low frequency range $(0$ to $-5 \mathrm{~dB}$ at $1 \mathrm{~Hz}$ ). Thus, the real performance of these transducers must be confirmed before their use in LHG journal bearings.

Finally, there is the uncertainty in the estimation of bracket stiffness, which may be experimental or theoretical, using the Finite Element Method (FEM). All these aspects indicate that the uncertainty of this and other similar methods may achieve significant values.

3.3.2. Discussion about a Monitoring Method. Much damage that frequently occurs in LHG changes the bearing operating conditions and the bearing parameters, the pads clearances, the lubricant viscosity, and the radial static load. Consequently, bearing dynamic coefficients will also change, altering LHG dynamics. These coefficients, bearing stiffness and bearing damping, have similar sensitivity to the changes in bearing parameters [12]. If bracket stiffness is known, bearing effective stiffness may be easily estimated by (5) and monitored for damage detection. Alternatively, as bearing bracket is less susceptive to damage, (5) may be used to determine the ratio between bearing effective stiffness and bracket stiffness, which may be also monitored for damage detection. To differentiate between the fluctuations in bearing stiffness originated by damage from the normal fluctuations, like those shown in Tables 8 and 9, the shaft eccentricity and the lubricant temperature shall be also monitored to properly characterize the bearing operating conditions. Then, damage detection is made by comparing bearing stiffnesses estimated in the same bearing operating conditions, reducing the possibilities of false-positive and false-negative errors. Finally, the effects of the journal bearing static radial load may be indirectly monitored by the bearing pads temperatures.

\section{Concluding Remarks}

The method discussed in this article experimentally estimates a kind of effective bearing stiffnesses, using solely the usually monitored shaft relative and bearing absolute vibrations, considering negligible cross-coupling effects. The method was validated by using vibration signals synthesized by a mathematical model that simulates the dynamic behavior of large hydrogenerators. In the validation process, the journal bearings were modeled as isotropic and anisotropic, as well as with and without cross-coupling effects. The maximum error obtained in this process was lower than $3 \%$.

The application of this method in a journal bearing of a $700 \mathrm{MW}$ hydrogenerator has shown that the bearing stiffnesses are usually one order of magnitude lower than the predicted theoretical values due to expressive dimensional changes in bearing housing, originated by thermal effects of the electromagnetic field induced in the bracket arms by the generator electrical outputs. This application also has shown that the bearing stiffness may increase significantly, in four times or more, due to unpredictable changes in bearing operating and boundary conditions, especially by changes in shaft eccentricity.

This indicates also that the theoretical determination of bearing stiffness, with an adequate accuracy, is unfeasible. The journal bearing operating conditions must be suitably monitored by all possible means. The shaft eccentricity should be measured with four-proximity-transducer arrangement to minimize the effect of thermal symmetric dimensional changes. The monitored parameters should include the temperatures of all bearing pads, the lubricant temperatures, the bearing cooling water temperatures, at inlet and at the outlet, the generator cold and hot air temperatures, and generator stator and rotor temperatures. The consequences of changes in these parameters in the bearing dynamic coefficients and in the large hydrogenerator dynamics must be understood and quantified, even using simplified models.

As large hydrogenerators in healthy conditions are balanced, the residual unbalance forces in the generator and turbine rotors are not able to excite the journal bearings adequately. This article has presented an alternative excitation, the hydraulic forces produced by the vortices created in Francis turbines when the hydrogenerator operates at partial loads. The amplitude of these forces may be varied on a given range by tuning the wicket gates opening in the partial load range.

This and other similar methods may have high uncertainty. In this specific case, the uncertainties mostly come from the transducers used to measure shaft relative and bearing absolute vibrations, as well as from the shaft mechanical runout and shaft electrical runout. This uncertainty may be reduced by replacing the piezoelectric accelerometers by suitable velocity transducers, with electronically extended lower cutoff frequency $(0.5 \mathrm{~Hz})$, to measure bearing absolute vibrations. This uncertainty may be also reduced by using four-transducer arrangement for measuring shaft relative vibrations, allowing the compensation of symmetric bearing dimensional changes.

\section{Conflicts of Interest}

The authors declare that there are no conflicts of interest regarding the publication of this paper.

\section{Acknowledgments}

The authors are grateful to Itaipu Binacional, the Itaipu Technological Park, and the Center for Advanced Studies on the Safety of Dams for the encouragement in this research. Roberto Dalledone Machado gratefully acknowledges the financial support provided by the Brazilian government agency $\mathrm{CNPq}$ (Conselho Nacional de Desenvolvimento 
Científico e Tecnológico) under the research grant 312241/ 2015-1.

\section{References}

[1] F. A. Hamill, "Sayano Shushenskaya accident: presenting a possible direct cause," International Water Power Dam Construction, pp. 30-36, 2010.

[2] L. A. Vladislavlev, Vibration of Hydro Units in Hydroelectric Power Plants, Amerind Publishing Company, New Delhi, India, 1979.

[3] R. B. Randall, Vibration-Based Condition Monitoring: Industrial, Aerospace and Automotive Applications, John Wiley \& Sons, 2011.

[4] Y. Wu, S. Li, S. Liu, H.-S. Dou, and Z. Qian, Vibration of hydraulic machinery, Springer, Dordrecht, Netherlands, 2013.

[5] C. R. Farrar and K. Worden, "An introduction to structural health monitoring," Philosophical Transactions of the Royal Society A, vol. 365, no. 1851, pp. 303-315, 2007.

[6] G. C. Brito Jr., "Application of simplified statistical models in hydro generating units health monitoring," in Damage Prognosis: for Aerospace, Civil and Mechanical Systems, pp. 451470, John Wiley \& Sons, Hoboken, NJ, USA, 2005.

[7] R. Cardinali, R. Nordmann, and A. Sperber, "Dynamic simulation of non-linear models of hydroelectric machinery," Mechanical Systems and Signal Processing, vol. 7, no. 1, pp. 29-44, 1993.

[8] A. A. Cavalini Jr., F. A. Lara-Molina, A. G. S. Dourado, and V. Steffen Jr., "Experimental uncertainty analysis of a flexible rotor supported by fluid film bearings," in Proceedings of the XVII International Symposium on Dynamic Problems of Mechanis, vol. 2015, Natal, Brazil.

[9] A. A. Cavalini Jr., A. G. S. Dourado, F. A. Lara-Molina, and V. Steffen Jr., "Uncertainty analysis of a tilting-pad journal bearing using fuzzy logic techniques," Journal of Vibration and Acoustics, vol. 138, no. 6, Article ID 061016, pp. 1-13, 2016.

[10] Itaipu Binacional, Projeto hidrelétrico de Itaipu: Características de Engenharia (Itaipu Hydroelectric Project: Engineering Characteristics), Tab Marketing Editorial, Porto Alegre, Brazil, 2009.

[11] R. Tiwari, A. W. Lees, and M. I. Friswell, "Identification of dynamic bearing parameters-a review," The Shock and Vibration Digest, vol. 36, no. 2, pp. 99-124, 2004.

[12] T. Someya, Journal-Bearing Databook, Springer, Berlin, Germany, 1989.

[13] T. Dimond, A. Younan, and P. Allaire, "A review of tilting pad bearing theory," International Journal of Rotating Machinery, vol. 2011, Article ID 908469, 23 pages, 2011.

[14] T. W. Dimond, P. N. Sheth, P. E. Allaire, and M. He, "Identification methods and test results for tilting pad and fixed geometry journal bearing dynamic coefficients-a review," Shock and Vibration, vol. 16, no. 1, pp. 13-43, 2009.

[15] R. K. Gustavsson, M. L. Lundström, and J.-O. Aidanpää, “Determination of journal bearing stiffness and damping at hydropower generators using strain gauges," in Proceedings of the PWR2005: ASME Power, Chicago, Ill, USA, April 2005.

[16] M. Nässelqvist, R. K. Gustavsson, and J.-O. Aidanpää, "Bearing load measurement in a hydropower unit using strain gauges installed inside a pivot pin," Experimental Mechanics, vol. 52, no. 4, pp. 361-369, 2012.

[17] M. Nässelqvist, R. K. Gustavsson, and J.-O. Aidanpää, "A methodology for protective vibration monitoring of hydropower units based on the mechanical properties," Journal of
Dynamic Systems, Measurement, and Control, vol. 135, no. 4, Article ID 041007, pp. 1-8, 2013.

[18] X. Young, L. Zhaohui, and L. Xide, "Dynamic model for hydroturbine generator units based on a database method for guide bearings," Shock and Vibration, vol. 20, no. 3, Article ID 120758, pp. 411-421, 2013.

[19] Itaipu, Medições especiais nos mancais da unidade 14 (Special measurements in unity 14 bearings), 1987.

[20] M. Nässelqvist, R. K. Gustavsson, and J. O. Aidanpää, "Resonance problems in vertical hydropower unit after turbine upgrade," in Proceedings of the JAHR - 24th Symposium on Hydraulic Machinery and Systems, Foz do Iguaçu, Brazil, 2008.

[21] R. Cardinali, Modelagem e aplicações em diagnose de máquinas rotativas verticais (Modeling and diagnostics applications in vertical rotating machines) [Doctoral thesis], Campinas State University, Campinas, Brazil, 1992.

[22] J. G. Fox and J. Mahanty, "The effective mass of an oscillating spring," American Journal of Physics, vol. 38, no. 1, pp. 98-100, 1970.

[23] J. C. Luneno, J. O. Aidanpää, and R. Gustavsson, "Model based analysis of coupled vibrations due to the combi-bearing in vertical hydroturbogenerator rotors," Journal of Vibration and Acoustics, vol. 133, no. 6, Article ID 061012, pp. 1-7, 2011.

[24] G. Genta, Dynamic of rotating systems, Springer, 2005.

[25] National Electrical Manufacturers Association, Installation of Vertical Hydraulic-Turbine-Driven Generators And Reversible Generators/Motors for Pumped Storage Installations-MG 5.2, NEMA, New York, NY, USA, 1972.

[26] A. Muszynska, Rotordynamics, Boca Raton: Taylor Francis Group, 2005.

[27] N. Littrell, "Understating and mitigating shaft runout," Orbit, vol. 3, pp. 5-17, 2005. 


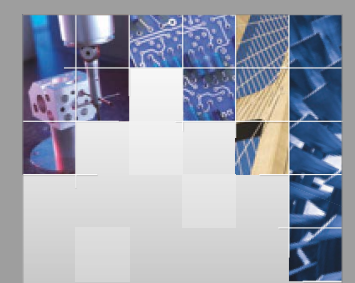

\section{Enfincering}
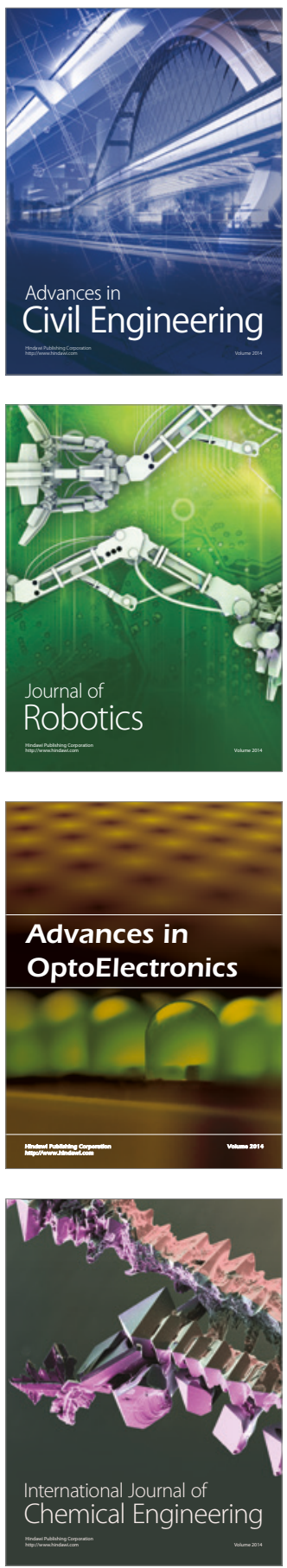

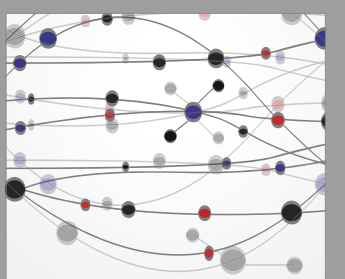

The Scientific World Journal

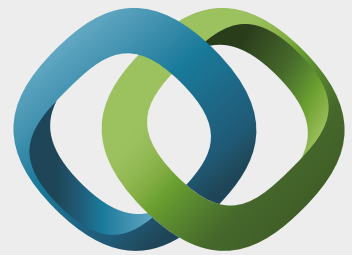

\section{Hindawi}

Submit your manuscripts at

https://www.hindawi.com
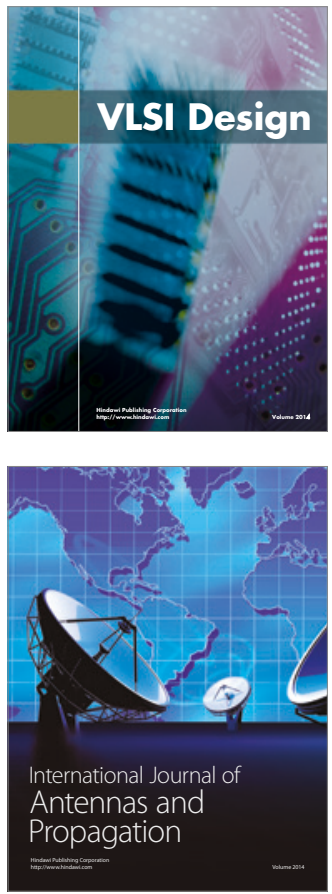

\section{Rotating}

Machinery
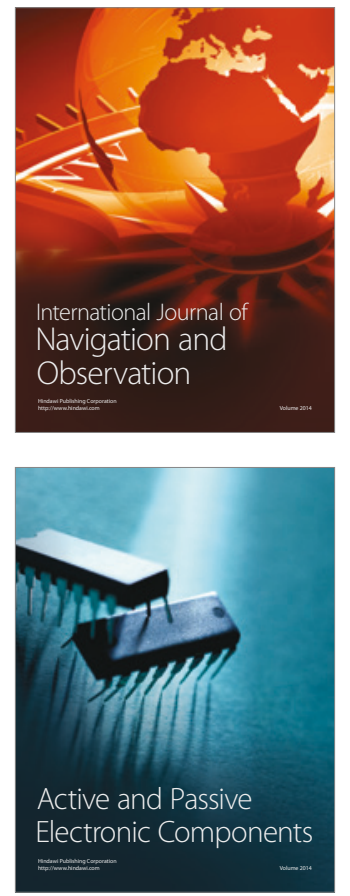
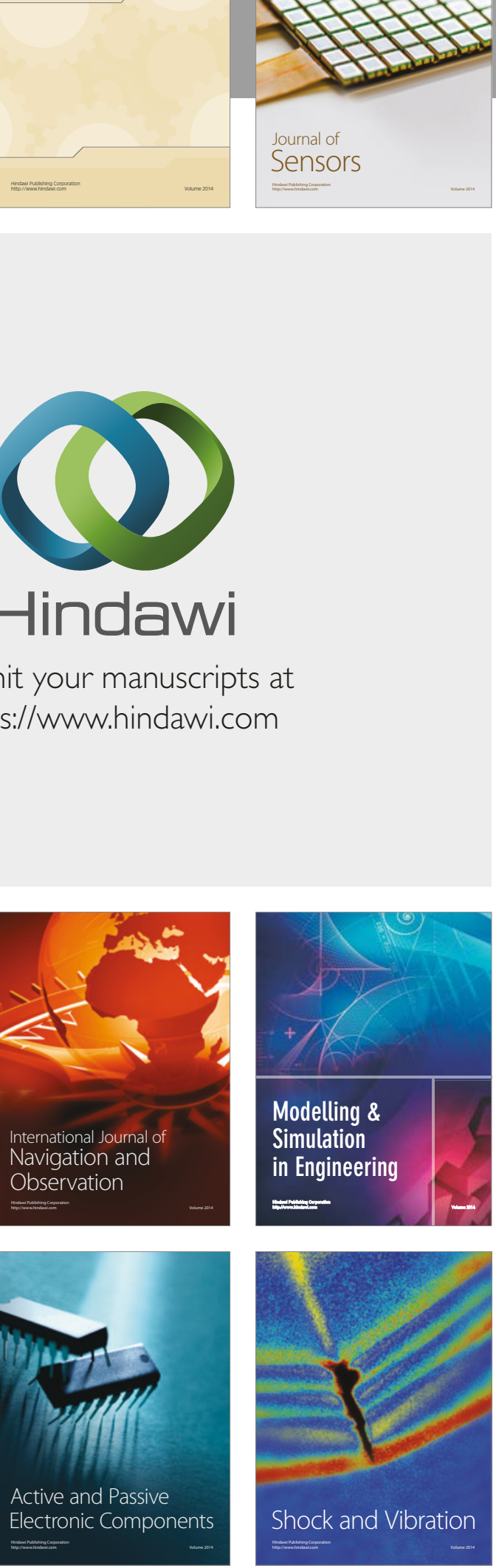
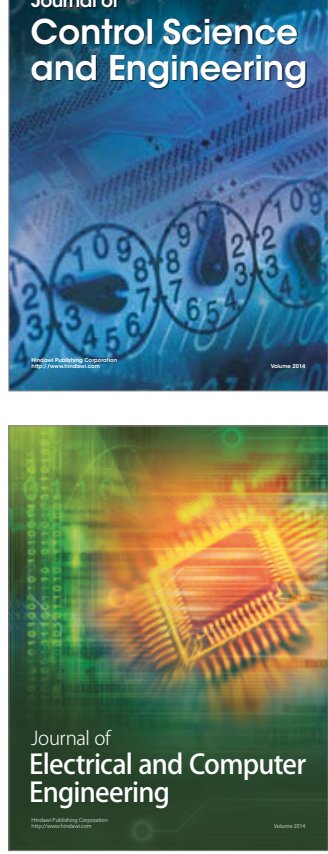

Distributed

Journal of

Control Science

and Engineering
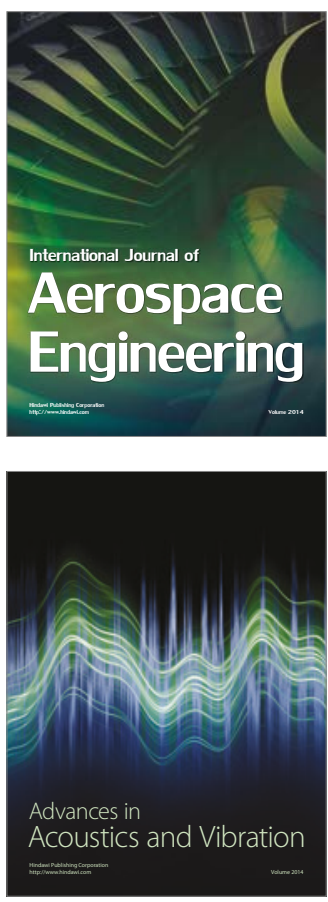

Sensor Networks 